\title{
REGULATION OF INFLAMMATION AND ANGIOGENESIS IN
}

THE CORNEA

Anthony Mukwaya

Division of Ophthalmology

Institute for Clinical and Experimental Medicine

Faculty of Health Sciences

Linköping University, Sweden

Linköping 2018

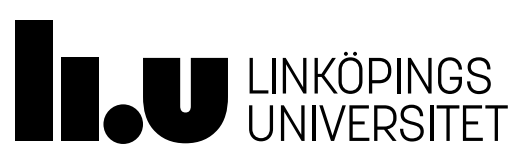


(C) Anthony Mukwaya, 2018

Cover illustration, and other images by Anthony Mukwaya

This thesis contains original material, and material reprinted from previously published work, published under a CC BY license (Creative Commons Attribution 4.0 International License), which allows for maximum dissemination and re-use of open access materials.

Published by Linköping University

Printed by LiU-Tryck, Linköping, Sweden, 2018

ISBN: 978-91-7685-284-2

ISSN: 0345-0082 
Regulation of inflammation and angiogenesis in the cornea

\author{
ACADEMIC THESIS By
}

Anthony Mukwaya

FOR THE AWARD OF A DOCTORATE DEGREE (Ph.D.)

By

Linköping University,

Institute for Clinical and Experimental Medicine,

Faculty of Health Sciences,

Linköping University, Sweden

\title{
Examination held at
}

Nils Holgersalen,

\section{Friday $1^{\text {st }}$ June $2018,13: 00 \mathrm{hrs}$}

\section{Main Supervisor:}

Neil Lagali, PhD Docent, Associate professor

Linköping University

Clinical and Experimental Medicine, IKE

Ophthalmology

\section{Co-Supervisor:}

Beatrice Bourghardt Peebo, MD PhD

Linköping University

Clinical and Experimental Medicine, IKE,

Ophthalmology

Head of Ophthalmology, Medical Affairs, Bayer $\mathrm{AB}$, Solna, Sweden.

Position at Bayer from first of September 2017, including 20\% as assistant Professor at IKE

\section{Co-Supervisor:}

Lasse Jensen, $\mathrm{PhD}$

Linköping University

Department of Medicine and Health, IMH

Cardiovascular medicine

\section{Faculty opponent:}

Thomas Ritter, PhD Professor of Medicine College of Medicine, Nursing and Health Sciences, National University of Ireland,

Galway, Ireland

\section{Examination board:}

Xiao-Feng Sun, $\mathrm{PhD}$, Professor

Linköping University

Clinical and Experimental Medicine, IKE

Orthopedics and oncology

Jesper Hjortdal, MD PhD Professor

Department of Ophthalmology

Division of Clinical Medicine

Århus University, Århus, Denmark

Maria Jenmalm, PhD Professor

Linköping University

Clinical and Experimental Medicine, IKE

AIR Enheten

Jan Ernerudh, MD PhD Professor

Linkoping university

Clinical and Experimental Medicine, IKE

Clinical Immunology 

"The most beautiful thing we can experience is the mysterious. It is the source of all true art and science".

- Albert Einstein 



\section{ABSTRACT}

Inflammation and angiogenesis, the growth of new blood vessels from pre-existing ones, are involved in tumor growth, ocular diseases and wound healing. In ocular angiogenesis, new pathological vessels grow into a specific eye tissue, leak fluid, and disrupt vision. The development of safe and effective therapies for ocular angiogenesis is of great importance for preventing blindness, given that current treatments have limited efficacy or are associated with undesirable side effects. The search for alternative treatment targets requires a deeper understanding of inflammation and how it can lead to angiogenesis in the eye in pathologic situations. This thesis provides new insights into the regulation of inflammation and angiogenesis, particularly at the gene expression and phenotypic levels, in different situations characterized by angiogenesis of the cornea, often called corneal neovascularization. For instance, specific genes and pathways are either endogenously activated or suppressed during active inflammation, wound healing, and during resolution of inflammation and angiogenesis, serving as potential targets to modulate the inflammatory and angiogenic response. In addition, as part of the healing response to restore corneal transparency, inflammation and angiogenesis subside with time in the cornea. In this context, LXR/RXR signaling was found to be activated in a time-dependent manner, to potentially regulate resolution of inflammation and angiogenesis. During regression of new angiogenic capillaries, ghost vessels and empty basement membrane sleeves are formed, which can persist in the cornea for a long time. Here, ghost vessels were found to facilitate subsequent revascularization of the cornea, while empty basement membrane sleeves did not revascularize. The revascularization response observed here was characterised by vasodilation, increased inflammatory cell infiltration and by sprouting at the front of the reperfused vessels. Importantly, reactive oxygen species and nitrous oxide signaling among other pro-inflammatory pathways were activated, and at the same time anti-inflammatory LXR/RXR signaling was inhibited. The interplay between activation and inhibition of these pathways highlights potential mechanisms that regulate corneal revascularization. When treating corneal neovascularization clinically, corticosteroids are in widespread use due to their effectiveness. To minimize the many undesirable side effects associated with corticosteroid use, however, identifying new and more selective agents is of great importance. Here, it was observed that corticosteroids not only suppressed pro-inflammatory chemokines and cytokines, but also activated the classical complement pathway. Classical complement may 
represent a candidate for further selective therapeutic manipulation to investigate its effect on treatment of corneal neovascularization.

In summary, this thesis identifies genes, pathways, and phenotypic responses involved in sprouting and remodeling of corneal capillaries, highlights novel pathways and factors that may regulate inflammation and angiogenesis in the cornea, and provides insights into regulation of capillary regression and re-activation. Further investigation of these regulatory mechanisms may offer alternative and effective targets for the treatment of corneal inflammation and angiogenesis. 


\section{SAMMANFATTNING}

Kärlnybildning, vilket innebär tillväxt av nya blodkärl, och inflammation är involverade i sårläkning, tumörtillväxt och vid en rad olika ögonsjukdomar. Vid kärlnybildning i ögat är de nybildade kärlen ofta omogna, vilket leder till att de läcker vätska, och skapar svullnad och blödning, som skadar ögats vävnader och ger synnedsättning. Utveckligen av säker och effektiv behandling av kärlnybildning i ögat har stor betydelse för att bättre kunna förhindra blindhet, inte minst då dagens behandlingar ofta är förenade med otillräcklig effekt och oönskade bieffekter. Sökandet efter nya behandlingsmetoder kräver en djupare förståelse av den inflammatoriska processen, och på vilket sätt den leder till kärlnybildning i ögat vid olika sjukliga tillstånd. Denna avhandling ger ny insikt i hur inflammation och kärlnybildning regleras, speciellt avseende genuttryck och fenotypnivåer, vid olika tillstånd med kärlnybildning i hornhinnan, också kallad korneal kärlnybildning. Olika gener och signaleringsvägar visade sig vara antingen endogent aktiverade eller hämmade vid pågående inflammation och sårläkning, respektive vid tillbakagång av inflammation och kärlnybildning, och skulle kunna utgöra alternativa behandlingsmål för att reglera tillväxt av blodkärlen. Som ett led vid sårläkning i hornhinnan, för att återskapa vävnadens klarhet, återgår långsamt inflammation och kärlnybildning. I samband med denna reaktion kunde det visas att $L X R / R X R$ signalering var tidsberoende aktiverat för att reglera tillbakagång av inflammation och kärlnybildning. Vid återbildning av de nybildade blodkärlen formades så kallade spökkärl och tomma basalmembranssträngar, vilka kan kvarstå under lång tid i hornhinnan. Det visade sig att spökkärlen underlättar revaskularisering i hornhinnan vid en ny skada medan de tomma basalmembranen lämnades opåverkade. Revaskulariseringen karakteriserades i nämnd ordning av; 1.vidgning av befintliga blodkärl (spökkärl), 2. infiltration av inflammatoriska celler och 3. nybildning av blodkärl, så kallad "sprouting", i toppen på de revaskulariserade spökkärlen. Parallellt noterades en aktivering av reaktiva syremolekyler och kväveoxidsignalering tillsammans med andra proinflammatoriska signaleringsvägar samtidigt som LXR/RXR aktivitet var hämmad. Samspelet mellan aktivering och hämning av dessa signaleringsvägar belyser viktiga mekanismer som reglerar kärlnybildning i hornhinnan. Vid behandling av korneal kärlnybildning i kliniken används idag kortikosteroider, ofta med god effekt, men också med hotande biverkningar såsom högt ögontryck (glaukom) och katarakt. För att minska risken för oönskade sidoeffekter är det av stor vikt att finna nya selektiva 
behandlingsmetoder. I denna avhandling visar det sig att kortikosteroider inte bara hämmar proinflammatoriska cytokiner utan också aktiverar klassiska komplementfaktorer. Det klassiska komplementet kan således utgöra en kandidat för framtida selektiv manipulering för att identifiera nya behandlingsprinciper av korneal kärlnybildning.

Sammanfattningsvis identifieras och belyses i avhandlingen gener, signaleringsvägar och fenotypnivåer som är involverade vid tillväxt och utmognad av inflammatorisk kärlnybildning i hornhinnan. Fynden ger en ny kännedom om reglermekanismer för nybildning och tillbakagång av sjukliga blodkärl, kunskap som i framtiden kan ge svar på hur inflammation och blodkärlstillväxt kan regleras och hämmas för att spara syn hos patienter med inflammatoriska och kärlnybildande tillstånd i ögats hornhinna. 


\section{LIST OF PUBLICATIONS INCLUDED THE THESIS}

I. Mukwaya A, Peebo BB, Xeroudaki M, Ali Z, Lennikov A, Jensen L, Lagali $\mathrm{N}$. Factors regulating capillary remodeling in a reversible model of inflammatory corneal angiogenesis. Sci Rep. 2016 Aug 26; 6:32137.

II. Mukwaya A, Lindvall JM, Xeroudaki M, Peebo BB, Ali Z, Lennikov A, Jensen LD, Lagali N. A microarray whole-genome gene expression dataset in a rat model of inflammatory corneal angiogenesis. Sci Data. 2016 Nov 22;3:160103

III. Mukwaya A, Lennikov A, Xeroudaki M, Mirabelli P, Lachota M, Jensen L, Peebo BB, Lagali N. Time-dependent LXR/RXR pathway modulation characterizes capillary remodeling in inflammatory corneal neovascularization. Angiogenesis. 2018 May;21(2):395-413.

IV. Mukwaya A, Lennikov A, Mirabelli P, Thangavelu M, Peebo BB, Jensen LD, and Lagali $\mathrm{N}$. Excessive inflammation and angiogenesis characterizes vascular rebound in the murine cornea. Manuscript (2018).

V. Mirabelli P\#, Mukwaya A\#, Lennikov A, Xeroudaki M, Peebo B, Schaupper $M$, Lagali N. Genome-wide expression differences in anti-Vegf and dexamethasone treatment of inflammatory angiogenesis in the rat cornea. Sci Rep. 2017 Aug 15; 7(1):7616.

\# denotes equal contribution

VI. Mukwaya A, Mirabelli P, Lennikov A, Xeroudaki M, Schaupper M, Peebo B, Lagali N. Genome-wide expression datasets of anti-VEGF and dexamethasone treatment of angiogenesis in the rat cornea. Sci Data. 2017 Aug 15;4:170111

Associated data citations

I. Mukwaya A, Mirabelli P, Lennikov A, Xeroudaki M, Schaupper M, Peebo B, Lagali N. Genome-wide expression datasets of anti-VEGF and dexamethasone treatment of angiogenesis in the rat cornea. NCBI Gene Expression Omnibus GSE87330 (2017).

II. Mukwaya A, Peebo B, Xeroudaki M, Ali Z, Lennikov A, Jensen L, Lagali N. A microarray whole-genome gene expression dataset in a rat model of inflammatory corneal angiogenesis. NCBI Gene Expression Omnibus GSE81418 (2016). 


\section{RELATED PUBLICATIONS NOT INCLUDED IN THE THESIS}

I. Lennikov A, Mirabelli P, Mukwaya A, Schaupper M, Thangavelu M, Lachota M, Ali Z, Jensen L, Lagali N. Selective IKK2 inhibitor IMD0354 disrupts NF$\mathrm{KB}$ signaling to suppress corneal inflammation and angiogenesis. Angiogenesis. 2018 May; 21(2):267-285.

II. Harada F, Morikawa T, Lennikov A, Mukwaya A, Schaupper M, Uehara O, Takai R, Yoshida K, Sato J, Horie Y, Sakaguchi H, Wu CZ, Abiko Y, Lagali N, Kitaichi N. Protective Effects of Oral Astaxanthin Nanopowder against Ultraviolet-Induced Photokeratitis in Mice. Oxid Med Cell Longev. 2017; 2017:1956104.

III. Ali Z, Mukwaya A, Biesemeier A, Ntzouni N, Ramsköld D, Giatrellis S, Mammadzada P, Cao R, Lennikov A, Rossi A, Marass M, Stone O, Deng Q, Peebo BB, Peso L, Kvanta A, Belting $H$, Affolter M, Sandberg R, Schraermeyer U, Andre H, Steffensen JF, Stainier DY, Lagali N, Cao Y, Kele $\mathrm{J}$, and Jensen LD. Productive and non-productive intussusception as a novel mechanism of occult choroidal neovascularization in wet AMD. Manuscript (2018). 


\section{TABLE OF CONTENTS}

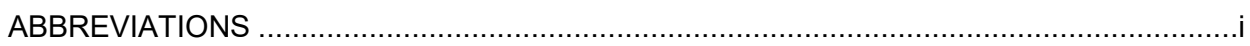

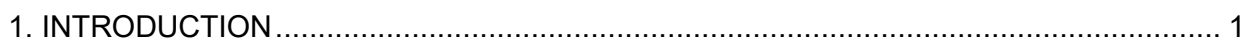

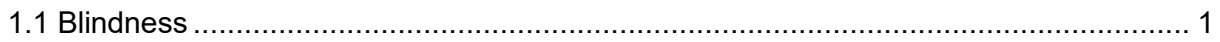

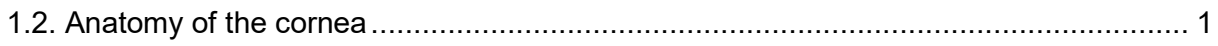

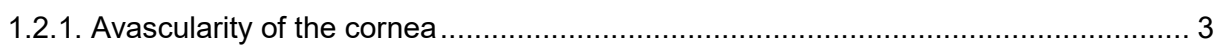

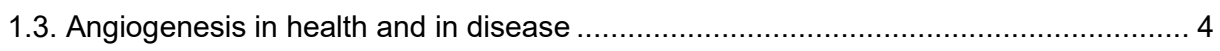

1.4. The crosstalk between inflammation and angiogenesis........................................ 5

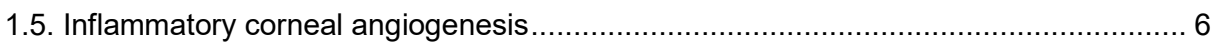

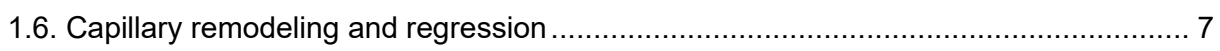

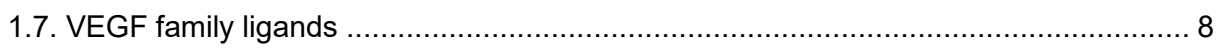

1.8. Treatment of corneal neovascularization ........................................................... 10

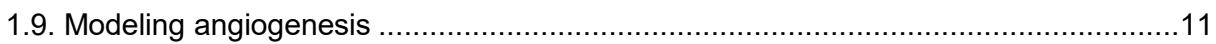

2. RESEARCH QUESTIONS AND FINDINGS IN THIS THESIS ...................................15

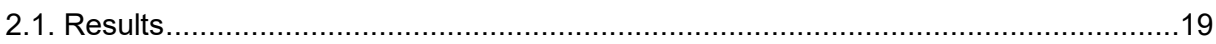

2.1.1. Upregulation of pro-maturation and suppression of pro-inflammatory genes drives capillary remodeling and regression in inflammatory corneal angiogenesis (PAPERS I \& II).

2.1.2. $L X R / R X R$ activation suppresses corneal inflammation time dependently (PAPER

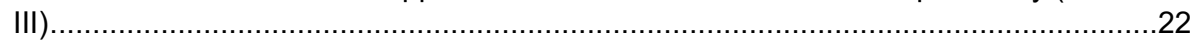

2.1.3. Ghost vessels facilitate rapid corneal revascularization (PAPER IV) ...................25

2.1.4. Corticosteroid treatment suppresses pro-inflammatory genes and activates

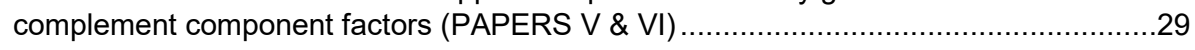

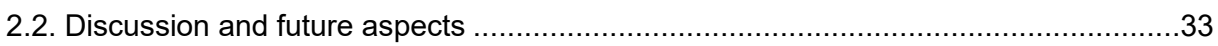

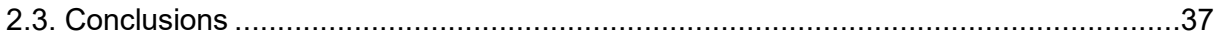

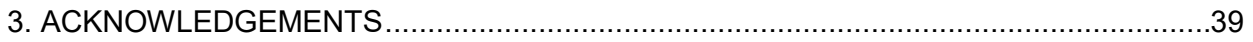

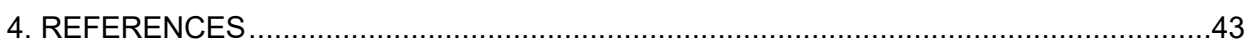

5. APPENDIX: Publications and a manuscript used in the thesis.....................................57 



\section{ABBREVIATIONS}

$\begin{array}{ll}\text { ARVO } & \text { The Association for research in vision and ophthalmology } \\ \text { BSA } & \text { Bovin Serum Albumin } \\ \text { CCL } & \text { Chemokine C-C motif ligand } \\ \text { CD } & \text { Cluster of differentiation } \\ \text { CDNA } & \text { Complementary DNA } \\ \text { CNV } & \text { Choroidal neovascularisation } \\ \text { CRNA } & \text { Complementary RNA } \\ \text { CXCL } & \text { Chemokine C-X-C motif ligand } \\ \text { DAPI } & \text { 4', 6-diamidino-2-phenylindole } \\ \text { DME } & \text { Diabetic macular edema } \\ \text { DR } & \text { Diabetic retinopathy } \\ \text { EC } & \text { Endothelial cells } \\ \text { ECM } & \text { Extracellular matrix } \\ \text { GAPDH } & \text { Glyceraldehyde 3-phosphate dehydrogenase } \\ \text { HUVECs } & \text { Human umbilical vein endothelial cells } \\ \text { IHC } & \text { Immunohistochemistry } \\ \text { IL } & \text { Interleukin } \\ \text { IVCM } & \text { In vivo confocal microscopy } \\ \text { IVT } & \text { In Vitro Transcription } \\ \text { LXR } & \text { Liver X receptors } \\ \text { LXRE } & \text { Liver X receptor response element } \\ \text { PBS } & \text { Phosphate buffered Saline } \\ \text { PCR } & \text { Polymerase Chain Reaction } \\ \text { PFA } & \text { Paraformaldehyde } \\ \text { PPAR } & \text { Peroxisome proliferator-activated receptor } \\ \text { qRTPCR } & \text { Quantitative real time polymerase chain reaction } \\ \text { RIN } & \text { RNA integrity number } \\ \text { RNA } & \text { Ribonucleic Acid } \\ \text { ROP } & \text { Retinopathy of prematurity } \\ \text { RVO } & \text { Retinal vein occlusion } \\ \text { RXR } & \text { Retinoid X receptors } \\ \text { SS-CDNA } & \text { Single-Stranded cDNA } \\ \text { ST } & \text { Sense Target } \\ \text { TAC } & \text { Transcription analysis console } \\ \text { TdT } & \text { Terminal deoxynucleotidyl transferase } \\ \text { UDG } & \text { Uracil-DNA glycoslase } \\ \text { VEGF } & \text { Vascular endothelial growth factor } \\ \text { WT } & \text { Whole Transcript } \\ & \end{array}$

Genes and protein names in this thesis have been formatted according to the bioscience writer guidelines available at:

http://www.biosciencewriters.com/Guidelines-for-Formatting-Gene-and-ProteinNames.aspx. 



\section{INTRODUCTION}

\subsection{Blindness}

Blindness can be defined as the inability to see either clearly or completely. Being blind reduces the quality of life ${ }^{1}$, increases the risk of death ${ }^{2}$ and can be an economic burden for the affected ${ }^{3}$. The World Health Organization (WHO) estimates that 253 million people live with vision impairment worldwide, of these 36 million are blind, and 217 million have moderate to severe vision impairment ${ }^{4}$. Globally, corneal blindness is the fourth largest cause of blindness and is one of the major causes of visual deficiency after cataract, glaucoma and age-related macular degeneration (AMD) ${ }^{5}$. Corneal blindness can be caused by trauma and ulceration ${ }^{6}$, by childhood corneal blindness ${ }^{5,7}$ or by infections such as trachoma ${ }^{8}$. Several of these causes are associated with inflammation and angiogenesis in the cornea, which in turn can cause persistent inflammation and scarring, irreversibly affecting the transparency of this tissue, thus reducing vision. Angiogenesis is defined as the growth of new blood vessels from pre-existing ones, and angiogenesis of the cornea is often called corneal neovascularization. As of today, there are no safe and effective treatments specifically targeting corneal neovascularization, making it a major clinical challenge in ophthalmology. As a contribution towards addressing this challenge, work in this thesis focused on gaining a better understanding of inflammation and angiogenesis in the cornea, by identifying genes and pathways that regulate these processes using an inflammatory corneal model of angiogenesis.

\subsection{Anatomy of the cornea}

The cornea is the outermost part of the eye that serves to protect the eye from mechanical injury. Transparency of the cornea allows for the transmission of light for proper vision, while its curved refractive nature is responsible for focusing light onto the retina for proper vision ${ }^{9}$, with $2 / 3$ of the light refracted in the cornea. The cornea consists of five distinct anatomic layers; epithelium, Bowman's layer, stroma, Descement's membrane, and endothelium. The epithelium is the outermost layer and measures approximately 50 microns in thickness in humans. Anteriorly, the epithelium is kept moist by the tear film. The epithelium is stratified into several cell layers. The basal layer of epithelial cells is the most posterior layer and is attached to the 
underlying basal lamina (or basement membrane) by hemidesmosomes and adhesion complexes. Epithelial cells are attached to each other via tight junctions, a characteristic important for the physical and chemical barrier function of the epithelium 9. The corneal epithelium is one of the mostly densely innervated structures of the body, a property important for survival of the epithelial cells, protection of the epithelium from external stimuli (through the blink reflex) and for the wound healing function of epithelial cells. A self-renewing ability of the epithelium facilitates continuous repair in case of epithelial damage. The tear film oxygenates the epithelium so that it does not require a direct blood supply, and the tears contain factors important for epithelial wound healing. Beneath the epithelium is 8-14 microns thick Bowman's layer, which is composed of a thin acellular layer composed of randomly-oriented Type I and $\mathrm{V}$ collagen fibrils and proteoglycans (Fig.1).

A

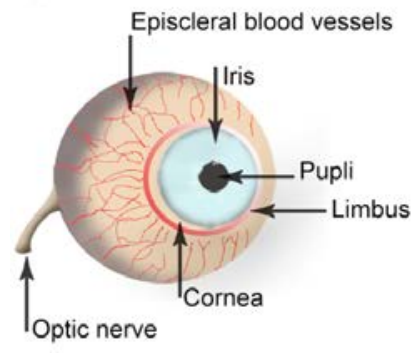

B

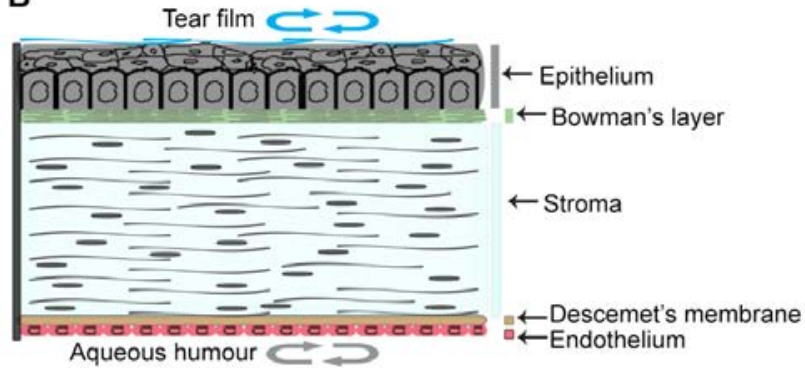

Figure 1. Schematic representation of an eyeball, and the cross section of the cornea. A is an eyeball identifying the cornea among other parts. $\mathbf{B}$ is a cross sectional representation of the cornea showing the different layers that comprise the cornea. The cornea is bathed anteriorly by a tear film, which is depicted by the blue circular arrows, and is bathed posteriorly by the aqueous humour, depicted by the grey circular arrows in B above. The schematic of the cornea in B is not to scale.

Posterior to the Bowman's layer is the stroma, which constitutes $80-90 \%$ of the entire corneal thickness. The stroma consists mainly of collagen fibers (Type I and V). These collagen fibrils run parallel to each other to form layers (or lamellae), which in turn are stacked with perpendicular orientation of the collagen fibrils between adjacent lamellae. The collagen fibril diameter and periodicity are important for minimizing light scatter and this configuration is believed to be the origin of corneal transparency ${ }^{10}$. Posterior to the stroma is the Descemet's membrane, which consists of Type IV and Type VIII collagen. The Descemet's membrane is continuously deposited throughout life by the endothelium, and thus gets thicker with age ${ }^{9}$. 
Posteriorly, the cornea is covered by the endothelium, a single layer of cells which maintains a fluid and ion balance between the stroma and the anterior chamber, by actively pumping fluid, keeping the stroma properly hydrated to maintain optimal transparency. The cells of the endothelium are metabolically active, and the aqueous humor provides the required nutrients to the endothelium and to the cornea in general, mainly by passive diffusion ${ }^{11}$, to prevent formation of edematous haze ${ }^{12}$, which would otherwise affect transparency of this tissue. Corneal endothelium should not be confused with vascular endothelium, which are two different cell types, and although they share the same name (endothelium), they have very different functions.

\subsubsection{Avascularity of the cornea}

The term "angiogenic privilege" refers to the ability of the cornea to maintain avascularity by preventing neovascularization from the surrounding tissues. Avascularity of the cornea has been attributed to factors such as the expression of soluble VEGF receptor-1 (sVEGFR-1 or sflt1), which binds and blocks the activity of vascular endothelial cell growth factor (VEGF)-A to prevent angiogenesis ${ }^{13}$. Mutations in genes such as paired box protein Pax-6 (Pax6), a gene important for the development of the eye, results in aniridia and spontaneous corneal neovascularization ${ }^{14,15}$ due to the lack of SVEGFR-1 ${ }^{16}$. In addition, the presence of anti-angiogenic molecules within the cornea are thought to contribute to the avascularity of this tissue ${ }^{17}$. For example, thrombospondin-1 (TSP-1) and thrombospondin-2 (TSP-2) members of the thrombospodin family are expressed in the healthy native cornea ${ }^{18}$, and were shown to have anti-angiogenic properties ${ }^{19,20}$. Other examples of anti-angiogenic mediators normally present in the cornea include endostatins ${ }^{21}$, angiostatins, and pigment epithelial-derived factor (PEDF) ${ }^{22}$. Apart from factors at the molecular level, anatomically, the dense collagen fibers, and the barrier function of limbal cells are also thought to contribute to the avascular nature of this tissue ${ }^{23}$. However, when the cornea is stimulated leading to inflammation, proangiogenic factors are activated and outweigh these anti-angiogenic factors, leading to neovascularization of the cornea. 


\subsection{Angiogenesis in health and in disease}

The formation of new blood vessels from pre-existing ones (angiogenesis) is a tightly regulated process mediated by factors such as vascular endothelial growth factor (VEGF), transforming growth factor (TGF), or by family members of the platelet derived growth factor (PDGF) among others. Angiogenesis differs from vasculogenesis, the latter referring to the de novo formation of blood vessels during development. Angiogenesis occurs in both health and in disease. Blood vessels of the central nervous system expand via angiogenesis ${ }^{24,25}$. In the developing retina, hypoxia in retinal astrocytes leads to the expression of VEGF ${ }^{26}$ resulting in angiogenesis ${ }^{27}$ to meet the oxygen demands of the tissue. In disease, such as in tumor angiogenesis, hypoxia is the main driving force for this pathology ${ }^{28,29}$. Hypoxia results from excessive tumor growth such that tumor tissue extends beyond the reach of the existing vasculature, leading to inadequate perfusion ${ }^{30}$. Activation of transcriptional factors (mainly HIF1 $\alpha$ ) by hypoxia leads to the expression of target genes that include VEGF$A^{31}$ to promote angiogenesis. In ocular pathologies such as in proliferative diabetic retinopathy, hypoxia resulting from capillary occlusion drives angiogenesis by promoting expression of angiogenic factors via HIF1 $\alpha$ activation ${ }^{32,33}$. In corneal neovascularization (described in detail below), for instance after injury, an early inflammatory response leads to the expression of pro-angiogenic factors including VEGF-A, that promote neovascularization ${ }^{34,35}$.

Overall, angiogenesis involves a sequence of events. The pre-existing vessels from which the new vessels emerge are in a state of quiescence stabilized by mural cells (or pericytes) and by basement membrane ${ }^{36}$. In a pre-angiogenic phase (for example during inflammation), these supporting structures are degraded by matrix-degrading proteases ${ }^{37}$. The activated vascular endothelial cell then leads the way as a tip cell of the newly forming vessel. The tip cell extends filopodia along the angiogenic molecule concentration gradient(s) ${ }^{38,39}$. The tip cell is followed by a stalk cell, which is highly proliferative, and establishes tight junctions to stabilize the newly forming vessel 40,41 . The interplay between stalk and tip cell phenotype is key for efficiency and directionality of the angiogenic response ${ }^{42}$. This phenotype is characterized by distinctive expression profiles for example of VEGR2 and Delta-like ligand 4 (DLL4) by the endothelial cells. Signaling of the tip cell through VEGFA/VEGFR2 enhances the expression of DII4, the ligand for Notch, and instructs the neighboring endothelial cell 
via DII4/Notch1 to become the stalk cell. The stalk cell responds by downregulating VEGFR2 and DII4 ${ }^{43}$, limiting the tip cell phenotype ${ }^{44,45}$. Angiogenesis involving sprouting of new vessels constitutes sprouting angiogenesis, the main form of angiogenesis modelled in this thesis. Besides sprouting angiogenesis, other forms of angiogenesis have been described and they include intussusceptive angiogenesis 46 and looping angiogenesis ${ }^{47}$. Intussuceptive angiogenesis is thought to occur in mature capillaries, characterised by the formation of intraluminal pillars within the vessel, mediated by shear stress ${ }^{48}$, to divide the vessel into two separate functional vessels. In corneal angiogenesis, intussusceptive angiogenesis has been observed during capillary remodeling ${ }^{49}$, and is thought to be a means of expanding the number of circulatory conduits within the neovascularised tissue, without new sprouting.

\subsection{The crosstalk between inflammation and angiogenesis}

In a broad sense, inflammation is the body's response to infection or external stimulation, and is characterized by swelling, redness, heat and pain. In addition to defending the body against pathogens, inflammation can affect the surrounding tissue to promote angiogenesis as part of a wound healing response. During inflammation, leukocytes enter the affected site by a process of leukocyte rolling, activation, adhesion and extravasation from pre-existing vessels, followed by migration to the site of injury ${ }^{50}$. These cells express early response inflammatory mediators such as IL-1 $\alpha, I L-1 \beta$ and TNF- $\alpha{ }^{51}$ to further promote inflammation. TNF- $\alpha$ acts by upregulating VCAM-1 and ICAM-1 in endothelial cells, mediated by endothelial cell Ang-2 to enhance further leukocyte extravasation. Ang-2 serves to amplify the effects of TNF$\alpha$, given that TNF- $\alpha$ is of suboptimal concentrations at this early stage of the inflammatory response ${ }^{52}$. This interplay between Ang-2 and TNF- $\alpha$ is an example of the crosstalk between inflammation and angiogenesis. In addition, the proinflammatory mediators $\mathrm{IL}-1 \beta$ and IL-1 $\alpha$ enhance endothelial cell proliferation by stimulating increased expression of VEGF ${ }^{53}$. From a clinical standpoint, ocular diseases such as pterygium ${ }^{54}$, diabetic retinopathy 55,55 and choroidal neovascularization ${ }^{56}$ all involve a component of inflammation and angiogenesis. With the currently available evidence 57,58 it is tempting to speculate that inflammation and angiogenesis are mutually interdependent processes. 


\subsection{Inflammatory corneal angiogenesis}

The angiogenic privilege of the cornea can be impaired by inflammation resulting from a range of stimuli such as infection, injury, and extended use of contact lenses leading to hypoxia 59,60,61. Following corneal injury, necrosis of corneal cells can lead to expression of cytokines and chemokines ${ }^{62}$ to promote inflammation. For example, II$1 \alpha$ is expressed in the cornea following injury ${ }^{63}$, promoting expression of proinflammatory mediators from corneal epithelial cells ${ }^{64}$. Cytokines such as IL-1 ${ }^{65}$, and Ccl2 ${ }^{66}$ are highly expressed in the injured cornea to promote inflammation by regulating recruitment of inflammatory cells ${ }^{67}$. Damage to the epithelium also results in the expression of many pro-angiogenic factors such as VEGF and TGF ${ }^{68,69}$. The vasculature of the limbal arcade responds to VEGF levels by dilating, presumably to facilitate inflammatory cell extravasation ${ }^{34,70,71}$, characterised by increased expression of adhesion molecules like ICAM-1 ${ }^{72}$ and VCAM-1 ${ }^{73}$. In addition, inflammation can lead to expression of proteases that degrade the extracellular matrix ${ }^{74,75}$ to promote corneal neovascularization. The infiltrating inflammatory cells can lead to edema in the stroma which occurs prior to, and may facilitate the neovascularization response. Neutrophils and monocytes secrete factors that lead to vasodilation and to recruitment of more inflammatory cells ${ }^{76}$. The recruited inflammatory cells express proinflammatory genes via activation of Nuclear Factor-KB (NfKB) pathway, to promote inflammation ${ }^{77,78}$.

Once angiogenic sprouting has initiated, the newly formed sprouts are immature and leaky, further promoting edema in the stroma ${ }^{79}$. Persistent inflammation, edema, and scarring affect the transparency of the cornea, hence reducing overall visual acuity.

Besides the formation of blood vessels from pre-existing ones (called hemangiogenesis), inflammation in the cornea can lead to the formation of lymphatic vessels from pre-existing lymphatic vessels (called lymphangiogenesis) ${ }^{80,81}$. Lymphangiogeness occurs in the cornea, but is delayed relative to hemangiogenesis 82. The lymph vessels serve to drain the tissue of excess fluid ${ }^{83,84}$. However, lymphatic vessels in the cornea can have adverse effects such promoting graft rejection by enhancing trafficking of antigens from the cornea to the regional lymph nodes via the transport of antigen presenting cells ${ }^{84}$. 
In an inflammatory response, the innate and adaptive arms of the immune system play different functions. The adaptive immune response develops slowly and is necessary for an efficient immune response. The innate immune response on the other hand is activated immediately by stimuli such as infection, to defend the host ${ }^{85}$. Innate immunity of the cornea involves cells such as epithelial cells which secrete TNF- $\alpha$, IL1, IL-6 and IL-8, and fibroblasts which secrete IL-1, IL-6, IL-8, TNF- $\alpha$, and $\alpha$-defensin, to fight infections ${ }^{86}$. Toll like receptors (TLRs) recognize pathogen-associated molecular patterns (PAMPs) on the surface of invading pathogens, to elicit an immune response ${ }^{87}$. TLRs link the innate immune response to the adaptive immune response by initiating inflammatory cell recruitment. In inflammatory corneal angiogenesis, neutrophils migrate to the injured site within a few hours after stimulation ${ }^{34}$. In addition, inflammatory cells such as dendritic cells, in turn present antigens to naïve T-cells to initiate the adaptive immune response ${ }^{88,86}$, to completely clear the invading pathogen. Complement is part of the innate immunity and serves to rapidly eliminate the invading pathogen by opsonization, and by activation of inflammation ${ }^{89}$.

\subsection{Capillary remodeling and regression}

Following corneal neovascularization, the fate of the newly formed vessels can be determined by either the continued presence or absence of an angiogenic stimulus over time. For example, removing the angiogenic stimulus (such as a foreign body) results in remodeling and regression of the newly formed vessels ${ }^{90}$. Remodeled vessels can become covered by pericytes, which makes them potentially resistant to anti-VEGF therapy, given that pericytes stabilize the capillaries, whereas anti-VEGF treatments efficiently target immature non-stabilized and leaky sprouts 91,92,93. Therefore, keeping capillaries in an immature state can be a means to avert resistance to anti-VEGF therapy. To achieve this, a better understanding of the process of capillary remodeling is required to identify potential factors regulating maturation. From studies in developmental angiogenesis ${ }^{94,95,96}$, and in adults ${ }^{97}$, different modes of capillary remodeling have been described, and these include endothelial cell apoptosis observed during hyaloid vessel regression ${ }^{98}$, and during pupillary membrane vessel regression 99,100,101. Endothelial cell migration as another mode or remodeling is observed in remodeling of zebrafish midbrain ${ }^{102}$. 
Perfusion of vessels is also key for their survival, and this is so because shear stress promotes endothelial cell survival through the Akt pathway and Krüppel-like factor 2 (KLF2) activation leading to the upregulation of nitric oxide(NO)-synthase and superoxide dismutase to mediate vasodilation ${ }^{103}$. In addition, inhibition of VEGF signaling induces capillary regression characterized by cessation of flow and by endothelial cell apoptosis 104,105. Another signaling axis implicated in capillary remodeling is Wnt signaling, which regulates endothelial cell migration, proliferation, and survival ${ }^{106}$. Angiopoietin and Tie signaling is also another axis involved in capillary remodeling and regression ${ }^{107}$. Overall, extensive capillary remodeling in the cornea over time can lead to the formation of persistent vascular networks, and VEGF-B, a member of the VEGF family of ligands, was shown to be important for the survival of a remodeled capillary bed, by promoting the activity of pro-survival genes neuropilin$1(\mathrm{NP}-1)$ and VEGFR-1 108 .

\subsection{VEGF family ligands}

The VEGF family of ligands are structurally related members including; VEGF-A, VEGF-B, VEGF-C, VEGF-D and placental growth factor (PIGF). Some of these are discussed below.

VEGF-A is an important growth factor involved in vasculogenesis and angiogenesis 109, and consists of different isoforms resulting from a single gene by process of alternative splicing ${ }^{110,111}$. In humans, VEGF-A has isoforms having 121, 145, 165, 189 and 206 amino acids 112,113,114,115, which differ in their affinity for heparin sulfate determined by their exon composition i.e. exons 6 and 7 are important for heparinbinding 116,117, and isoforms containing these exons are less diffusible. In murine species, VEGFA-164 is a homologue for the human VEGFA-165 isoform, and is the most abundant isoform ${ }^{118}$. VEGF-A is most studied for its role in angiogenesis ${ }^{119,120}$, and VEGFA-165 is the most potent isoform for angiogenesis ${ }^{121}$. VEGF-A signals via transmembrane tyrosine kinase receptors VEGFR-1(FLK-1) and VEGFR-2 (KDR). VEGFR-2 is expressed mainly by endothelial cells, and signaling through this receptor by VEGF can regulate processes such as cell proliferation and migration to promote angiogenesis ${ }^{122,123}$. VEGFR-1 is shown to heterodimerize with VEGFR-2 to regulate endothelial cell homeostasis ${ }^{124}$. In addition, VEGFR-1 binds VEGF-A with greater 
affinity compared to VEGFR-2, however, the kinase activity downstream of VEGFR-1 is weaker ${ }^{125}$, and VEGFA-VEGFR1 is shown to negatively regulate angiogenesis during embryogenesis ${ }^{126}$. VEGFA-VEGFR2 signaling is important for angiogenesis, and is the most studied pathway $127,122,125,128$.

In an inflammatory milieu, VEGF acts as a pro-inflammatory cytokine by promoting expression of cell adhesion molecules, other cytokines, and acts as a monocyte chemoattractant 129,130,131. Monocytes express VEGFR-1 and respond to VEGF by enhanced cell migration ${ }^{132}$, to further promote inflammation. A subpopulation of circulating neutrophils express VEGFR-1, and respond to VEGFA during inflammation 133. The central role of VEGF-A in angiogenesis has led to the development of antiVEGF treatments (discussed below) for tumor and for ocular angiogenesis; however, efficacy of anti-VEGF for example in treating corneal angiogenesis is variable, an effect partially explained by this thesis.

VEGF-B is expressed in many tissues, and by a range of cells including endothelial cells ${ }^{134,135}$. VEGF-B consists of two isoforms VEGFB-167 and VEGFB-186, both of which can heterodimerize with VEGF-A when co-expressed. VEGF-B 167 is speculated to determine the bioavailability of heterodimers to potentially control bioavailability of VEGF-A $125,136,137$. VEGF-B is not as well described as VEGF-A with regard to angiogenesis. From recent studies, the loss of VEGF-B in corneal angiogenesis does not affect neovascularization ${ }^{138}$. Deletion of VEGF-B during developmental angiogenesis is not lethal in mice, but rather causes cardiovascular abnormalities 138,139. However, in the developing zebrafish embryo, Vegfba knockdown is lethal, demonstrating the importance of VEGF-B in developmental angiogenesis in this model 140. Notably, developmental angiogenesis in zebrafish embryos is not hypoxiadependent as is the case in mice and other mammals ${ }^{141}$.

VEGF-C can signal via both VEGFR-2 and VEGFR-3, to regulate lymphangiogenesis mainly via VEGFR-3 ${ }^{142}$. VEGF-C is important during embryogenesis, as shown by lethality of mice containing a global deletion of this gene ${ }^{143}$. In adults, constitutive expression of VEGF-C regulates lymphangiogenesis via VEGFR-3 ${ }^{144}$. In addition, VEGF-C is known to stimulate lymphangiogenesis and hemanagiogenesis under inflammatory conditions ${ }^{145,142}$, and its expression can be induced by pro-inflammatory 
mediators such as TNF- $\alpha^{146}$. Lymphangiogenesis can also occur during inflammation in the cornea, but this was not the focus of this work.

\subsection{Treatment of corneal neovascularization}

Currently, treatments for corneal neovascularization include corticosteroids (often simply referred to as 'steroids') and non-steroidal anti-inflammatory drugs, laser photocoagulation ${ }^{147}$, fine needle diathermy ${ }^{148}$, and photodynamic therapy 149,150 . These treatments are of variable efficacy, and some treatments such as steroids have undesirable side effects ${ }^{151,152}$. Given that VEGF is an important angiogenic molecule for corneal neovascularization ${ }^{35}$, one could argue that targeting this molecule as a therapeutic intervention against corneal neovascularization would be ideal. Along these lines, the currently available anti-VEGF agents initially intended for treating tumor angiogenesis are now finding their way into ophthalmology for the treatment of ocular pathologies, but are used off-label in the cornea. For instance, bevacizumab (Avastin ${ }^{\circledR}$ ) is a recombinant full-length humanized monoclonal antibody against VEGF-A approved by the FDA for treating cancers ${ }^{153}$. Bevacizumab is used off-label for treating ocular pathologies such as age-related-macular degeneration, proliferative diabetic retinopathy, and retinopathy of prematurity 154,155, and for corneal neovascularization ${ }^{156,157,158}$.

On a positive note, some anti-VEGF treatments have been approved for treatment of ocular pathologies in the posterior eye, for instance Ranibizumab (Lucentis $®$ ) which comprises of the Fab fragment of the same mouse monoclonal antibody as bevacizumab ${ }^{159}$. This modification is meant to improve penetration efficiency of the antibody, given that the full-length antibody was found to poorly penetrate the retina 160 , though this is debatable ${ }^{161,162}$. Ranibizumab is approved for wet-AMD ${ }^{163}$, with efficacy similar to that of bevacizumab 164,165 . However, ranibizumab is much more expensive ${ }^{166}$, hence creating a potential economic burden. Another approved antiVEGF treatment is Pegaptanib (Macugen $®$ ), which is an aptamer that specifically binds $V_{E G F}{ }_{165}$. Pegaptanib is approved for treating the wet form of AMD ${ }^{167}$, but has only limited efficacy. Aflibercept (EYLEA®), another anti-VEGF treatment is a recombinant fusion protein of human VEGFR-1 and 2 extracellular domains fused to the Fc portion of human IgG1. Aflibercept acts as a VEGF trap sequestering VEGF-A, B and PIGF ${ }^{168,169}$ with high affinity, and reported to be of a longer intravitreal half-life ${ }^{170}$. Aflibercept 
is approved by the FDA for treating neovascular AMD ${ }^{171}$, diabetic macular edema $(D M E){ }^{172}$, retinal vein occlusion (RVO) ${ }^{173}$ and myopic choroidal neovascularisation $(\mathrm{CNV})^{174}$, and with promising results ${ }^{175}$.

In line with the gene therapy approach, Aganirsen (GS-101®) is a DNA antisense oligonucleotide targeting insulin receptor substrate-1 (IRS-1). Aganirsen has shown promise in inhibiting keratitis-induced corneal neovascularization ${ }^{176,177}$.

Of the currently available anti-VEGF treatments, none is yet approved for treating corneal neovascularization, and when used off-label, such agents are of limited efficacy as demonstrated experimentally and in clinical settings ${ }^{71,178,179}$. In addition, these treatments do not directly target inflammation. Gene-therapy based treatments are typically transient and are associated with off-target effects. These shortfalls highlight the need for alternative treatments.

\subsection{Modeling angiogenesis}

To identify alternative targets for improved treatment of corneal neovascularization requires the use of models that mimic the pathophysiology of the disease as closely as possible. The process of angiogenesis is complex in that it involves many different cell types and signaling molecules. However, many models have been developed over the years to study angiogenesis in contexts such as tumor angiogenesis, adipose tissue angiogenesis and ocular angiogenesis ${ }^{180}$. These include models such as the zebrafish model of angiogenesis which has been used to study tumor angiogenesis 181, retinal angiogenesis ${ }^{181}$, choroidal neovascularisation 182 and regenerative angiogenesis ${ }^{183}$. The rat ischemic hind limb model is important for addressing questions concerning impaired angiogenesis such as in wound healing, stroke and in myocardial infarction ${ }^{184,185}$. The oxygen induced retinopathy (OIR) model in mouse pups is another model that has been used extensively to investigate retinopathy of prematurity (ROP), yielding a better understanding of this pathology ${ }^{186}$. Another model system of angiogenesis is corneal angiogenesis. The cornea is naturally avascular, which means that all vessels that grow into the cornea are pathologic and a result of the stimulus. In other non-cornea models, pre-existing vessels are cofounding factors, which make it difficult to differentiate between the angiogenic and pre-existing vessels, particularly in vivo. In addition, transparency of the cornea means the newly formed 
vessels can easily be observed; since they are perfused with blood, the vessels appear as reddish/pinkish structures under a light microscope. The cornea is an externally accessible tissue, a property that allows for live in vivo imaging, for instance to document angiogenesis in a time-dependent manner ${ }^{34}$. Furthermore, compounds under investigation can easily be implanted in the cornea using an intra-stromal micropocket ${ }^{187}$, and medications can easily be given locally as eye drops or by subconjunctival injection ${ }^{188}$.

Use of the cornea as a tissue to study angiogenesis has been reported over the years, in models such as the mouse micropocket assay. The micropocket assay entails making a pouch intra-stromally in the cornea where the factor(s) under investigation are implanted in the form of a polymer pellet that slowly releases the substance 189,190 . This model has enabled investigation of angiogenic properties of molecules such as bFGF 191,192, VEGF, PDGF 190 and Fgf7 ${ }^{193}$. The model elucidates the angiogenic potential of single substances in isolation; however, if the angiogenic response in a physiological setting is to be studied, the multifactorial nature of angiogenesis and the role of inflammation are not adequately represented by this model.

More physiologic models of angiogenesis are inflammatory models, which are intended to mimic pathological scenarios of corneal neovascularization. For instance, alkaline cauterization/burn of the cornea using a mixture of silver nitrate or by $\mathrm{NaOH}$ induces inflammatory corneal angiogenesis ${ }^{194,195,196}$. The alkaline cauterization/burn model is effective, however, an investigator in this setting has limited control of the stimulus. In this thesis, being able to control the angiogenic stimulus was a key factor in deciding the model of choice. In particular, a model was sought where angiogenesis could be induced reproducibly and reversibly in the cornea, to study not only the neovascularization response but also vascular regression, remodeling, and revascularization by repeated stimulus. This brings us to the suture model of inflammatory corneal angiogenesis, which involves placing surgical sutures into the cornea intra-stromally (Fig. 2). The suture breaks the epithelial barrier and introduces a foreign body into the stroma to induce an inflammatory response, which in turn leads to angiogenesis. 

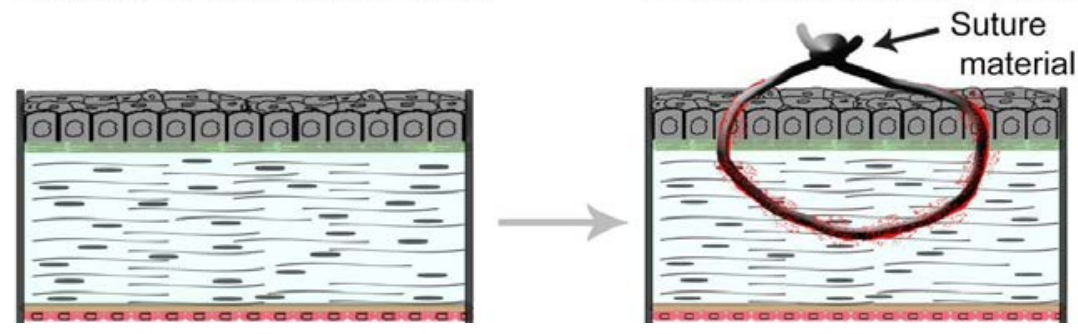

Figure 2. Schematic illustration of the suture model of inflammatory corneal angiogenesis, showing the suture traversing the corneal stroma before it exits to the surface where it is knotted to fasten it in place.

The neovascularization response in the suture model of inflammatory corneal angiogenesis can be controlled, depending on parameters such as the number of sutures, pattern and depth of suture placement, suture size and material, and the distance of the sutures to the limbus. The closer the sutures are to the limbus (where the pre-existing vessels are present), the faster the neovascularization response. The greater the number of sutures spread out across the cornea, the larger the neovascularized area. In a clinical setting, surgical sutures are placed into the cornea following corneal transplantation, and these sutures can trigger neovascularization, which is typically handled by postoperative prophylactic use of steroids. In this sense, the suture model is a clinically relevant model for corneal neovascularization, mimicking other pathologic situations leading to inflammation and angiogenesis in the cornea. In this thesis, the suture model of angiogenesis was used and is elaborated in detail in the later chapters.

Despite the benefits of the cornea as a model of angiogenesis, compared to other assays, the cornea model of angiogenesis can be considered relatively expensive since a single cornea can allow for a few laboratory downstream analyses, and is hence not a practical choice for larger screening purposes. For screening purposes, there are in vitro models typically using Human umbilical vein endothelial cells (HUVECs), but these do not replicate physiological parameters such as blood flow, and do not take other cell types (such as inflammatory cells) into account. In addition, assays such as the rat aortic ring, allow for quantitative angiogenesis, and can be transfected to study gene function ${ }^{197,198}$. Nevertheless, this in vitro assay does not also accurately mimic the physiological state of angiogenesis. The cornea itself has also been questioned as a suitable model for angiogenesis because of its angiogenic and 
immune privilege, meaning that it may not properly represent other tissues in the body, which already have a pre-existing vascular bed. Therefore, the different models and assays of angiogenesis should be seen as complementary to each other, with the research question under investigation guiding the choice of model to use. 


\section{RESEARCH QUESTIONS AND FINDINGS IN THIS THESIS}

Corneal neovascularization is a clinical challenge, mainly due to the lack of safe and effective treatments. Currently, anti-VEGF therapies are used off-label, and are of limited efficacy ${ }^{71}$. Steroids and nonsteroidal anti-inflammatory drugs (NSAIDs) are potent in blocking inflammation, but they are associated with undesirable side effects like corneal thinning and ulceration, cataract, glaucoma, corneal melting, and increased risk of infection 151,152. Alternative treatments such as gene therapy are under investigation ${ }^{199}$, however, these have drawbacks such as the transient nature 200 and immune reactivity ${ }^{201}$ of siRNAs, and their association with off-target effects ${ }^{202}$. Addressing these shortfalls requires a better understanding of the process of corneal neovascularization, which this thesis aims to address. The main research questions addressed in this thesis are:

1. Which genes are responsible for the rapid remodeling and maturation of newly formed angiogenic capillaries in the cornea, making them less susceptible to treatment?

2. How is inflammatory angiogenesis in the cornea regulated with time?

3. What are the characteristics and the role of ghost vessels in the cornea?

4. What are the important targets for corticosteroids, as a treatment for inflammatory corneal angiogenesis?

These lines of investigation are graphically illustrated in Fig. 3 below.

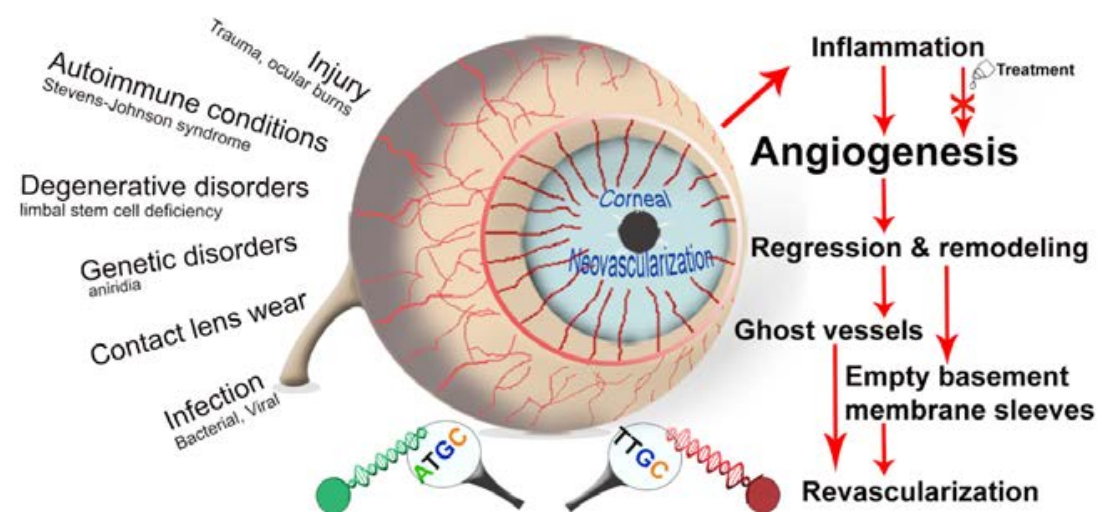

Figure 3. An overview of the lines of investigation in this thesis. Neovascularization of the cornea can be caused by stimuli such as injury, infections, contact lens wear for prolonged periods, or by genetic disorders such as aniridia. These stimuli cause inflammation of the cornea, which in turn can facilitate angiogenesis with sprouts originating from the limbus towards the center of the cornea (red lines from the red circle). Remodeling and regression of the hemangiogenic vessels leads to the formation of ghost 
vessels and empty basement membrane sleeves, which can persist in the cornea. The red arrows indicate the processes investigated within this thesis.

Following the research questions outlined above, this thesis addresses the following specific research objectives:

1. To identify the mediators of capillary remodeling and regression

2. To investigate possible time-dependent expression patterns of inflammatory angiogenesis

3. To better elucidate the role of corneal ghost vessels and basement membrane sleeves in a repeat event of corneal neovascularization

4. To identify key targets of corticosteroids in treating corneal neovascularization

To address these objectives, the suture model of inflammatory corneal angiogenesis in the rat was used. The rat was preferred over the mouse because the rat eye is larger (diameter of about $6.41 \mathrm{~mm}$ in rats and $3.32 \mathrm{~mm}$ in mice ${ }^{203}$, but both are much smaller compared to $28 \mathrm{~mm}$ in humans ${ }^{204}$ ). The rat eye therefore offers more surface area for in vivo examination and more tissue for laboratory downstream analysis from a single eye, a parameter important to minimize variation. One disadvantage of rat models is the difficulty in obtaining transgenic strains; for the purposes of this thesis gene knockdown was not required, but would be of interest in future work.

Importantly, the suture model of inflammatory corneal angiogenesis also offers control of the angiogenic stimulus, a property that was instrumental for studying regression and remodeling of capillaries, which was triggered by a timed removal of the angiogenic stimulus. In addition, the suture model is robust, highly reproducible and adaptable. Ease of reproducibly suturing the rat cornea and locating the suture site for analysis and re-suturing were also important considerations in the choice of species. Briefly, the model involved placing two sutures intrastromally into the cornea (at $1.5 \mathrm{~mm}$ from the limbus). The sutures induced an inflammatory response characterized by vasodilation of limbal vessels, and inflammatory cell extravasation and infiltration into the cornea, starting a few hours after suture placement. The migrating inflammatory cells express cytokines, chemokines and growth factors, building a concentration gradient towards the site of injury. This environment then leads to the sprouting of new capillaries from the limbal vessels in a direction towards the sutures. By day four after 
suture placement, the newly formed sprouts extend from the limbus to about half of the distance to the sutures (Fig.4).

A

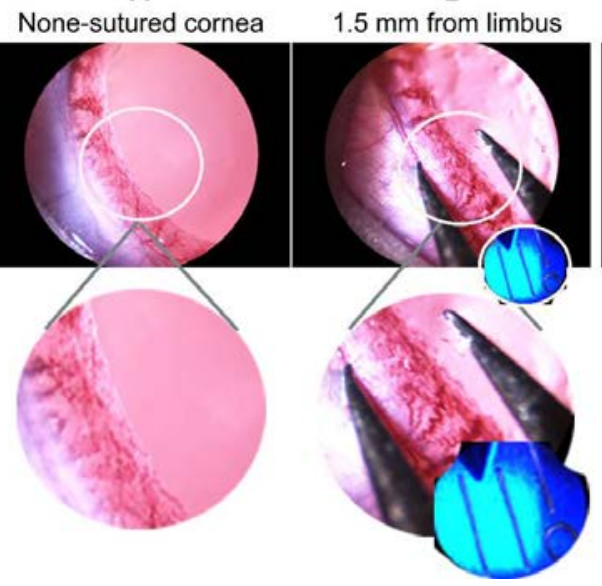

C

Sutures in place (Day 0) Newly formed sprouts (Day 4)

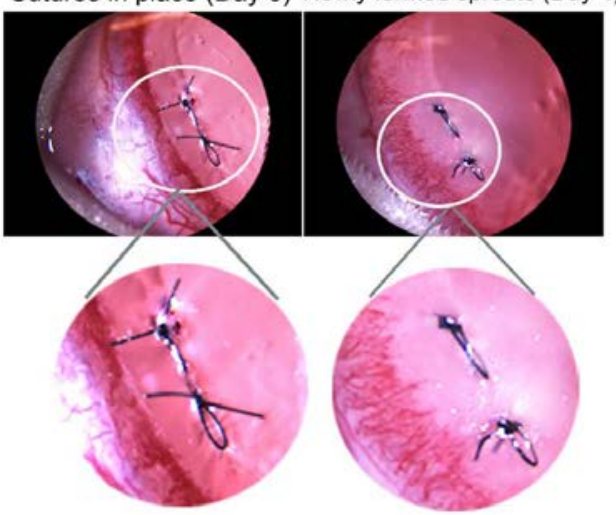

Figure 4. The suture model of inflammatory corneal angiogenesis used in this thesis. A. The appearance of a naïve cornea. The vessels observed are the iris vessels behind the cornea, and should not be confused with corneal vessels. B. The site for suture placement is determined using a Vernier caliper, corresponding to a distance of $1.5 \mathrm{~mm}$ from the limbus and marked at the eight and nine o'clock positions of the right eye. C. Two intra-stromal sutures are then placed at the demarcated sites using a wedge-shaped suture needle using 10-0 nylon sutures. After traversing the stroma, two knots are made on the surface of the epithelium to fasten the sutures in place. D. The sutured animals are then examined at various times after suture placement, starting from the first few hours. By day four after suture placement, capillary sprouts extend from the limbus to about halfway the distance to the sutures. This response is predictable and reproducible. Painkillers and antibiotics are used to manage pain and prevent infection, soon after suture placement and upon suture removal.

This model was used throughout this thesis with slight adjustments to meet the needs of each defined objective. The adjustments are detailed in the respective articles. Following neovascularization of the cornea, the sutured eye was examined using in vivo confocal microscopy (IVCM) and by a specialized slit lamp camera adapted for rodent eyes. In vivo analysis was instrumental for monitoring, and for the timedependent noninvasive analysis of the neovascularization response. Quantifiable indicators of inflammation and angiogenesis such as infiltrating inflammatory cell density, and the diameter of capillaries were determined from IVCM image sequences, and analysed. Vascular density was determined from slit lamp images, and analysed. Following euthanasia of the animals, ex vivo tissue analysis was limited to only the vascularized area of the cornea. The neovascularized area of the cornea was preserved in 'RNA-later' medium for gene expression analysis. Total RNA was extracted from the samples, and the quality verified prior to sample preparation for 
whole transcriptome analysis, performed mainly using GeneChip Rat 2.0 ST microarrays. As a verification of the microarray data, gene expression analysis was performed for specific genes of interest by qRTPCR, mainly using custom primers. Tissue for Western blot analysis was frozen at $-80^{\circ} \mathrm{C}$ until processing. Tissue for immunohistochemical analysis was frozen in optimal cutting temperature (OCT) media and temporarily stored at $-20^{\circ} \mathrm{C}$ until needed. Immunofluorescence was used to localize the expression of target genes in corneal cross-sections, and images were captured with a laser-scanning confocal fluorescence microscope. Statistical significance of quantifiable parameters was defined by a two-tailed $p$-value $<0.05$. The Shapiro-Wilk normality test was used to verify the normality of the data. Analysis of variance (ANOVA) was used when performing multiple comparisons and the Student$t$ test was used when comparing two independent groups. For the microarray data, differentially expressed genes were defined by the fold change, and by either $p$-value or false discovery rate (FDR), or both. Details of the methods and statistical considerations can be found in Papers I - VI.

The regional ethics committee for animal experiments in Linköping approved all animal experimental procedures under the ethical permit numbers (585 and 7-13) given in the respective papers. The conducted experiments were also in line with the Association for Research in Vision and Ophthalmology (ARVO) guidelines for the use of animals in vision research. 


\subsection{Results}

The findings herein describe the phenotypic characteristics associated with inflammatory corneal angiogenesis, and the associated dysregulated genes and pathways. In general, the results address each specific research question, one at a time.

\subsubsection{Upregulation of pro-maturation and suppression of pro-inflammatory genes drives capillary remodeling and regression in inflammatory corneal angiogenesis (PAPERS I \& II)}

To better understand the process of capillary remodeling thought to promote capillary resistance to anti-angiogenic treatments, the suture model of inflammatory corneal angiogenesis was used. Two intra-stromal sutures placed at $1.5 \mathrm{~mm}$ from the limbus in rat corneas induced sprouting of capillaries from the limbus towards the sutures. The sprouts extended halfway the distance from the limbus to the sutures by day four after suture placement. This time point of aggressive, active sprouting was re-named as the zero hour $(0 \mathrm{~h})$ time point, at which sutures were removed to induce capillary regression (Suture OUT). In another group, sutures were kept in place at Oh (Suture IN) to provide a continuous angiogenic stimulation, to serve as a positive control for the suture OUT group. For both groups, animals were subsequently examined at $24 \mathrm{~h}, 72 \mathrm{~h}$, and $120 \mathrm{~h}$ $(1,3$, and 5 days after the time point of sprouts extending halfway to the sutures). Microarray analysis (GeneChip Rat 2.0 ST arrays) was performed in the naïve, nonsutured corneas as a negative control, at the $0 \mathrm{~h}$ time point and at the $24 \mathrm{~h}$ time point in both suture IN and OUT groups. A total of four-microarray chips were used per group, with no pooling of samples (Fig.5). 

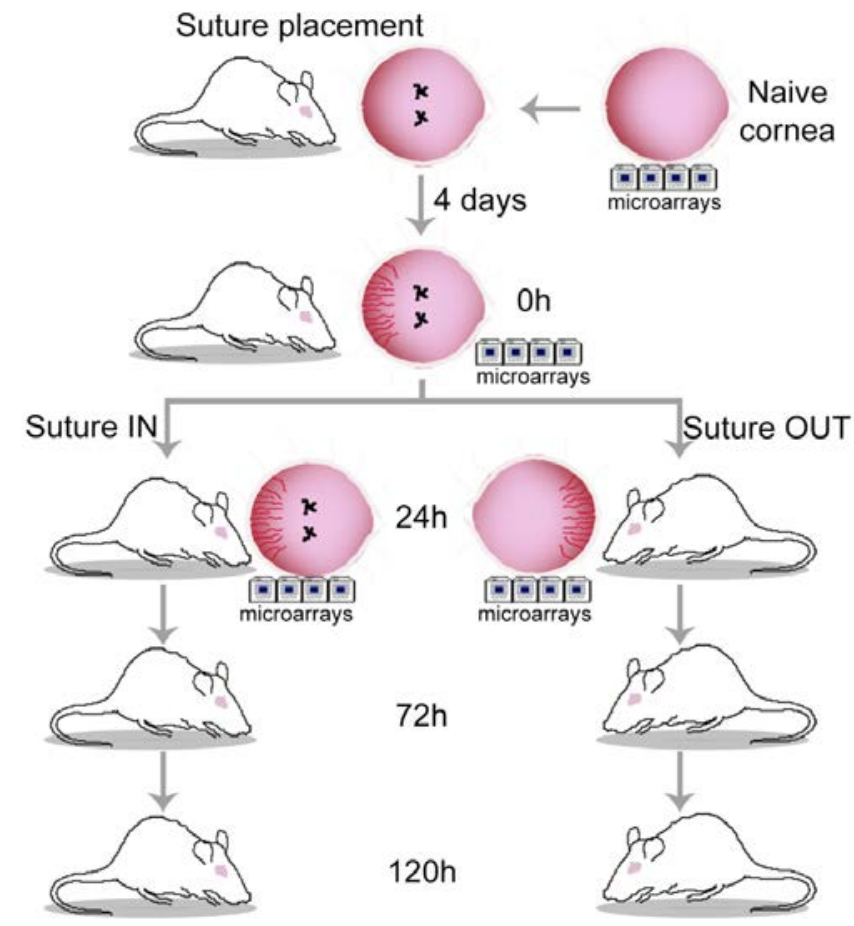

Figure 5. The experimental design used to characterize capillary remodeling and regression. Two sutures were placed into the cornea and sprouting was allowed to proceed for four days. On the fourth day (Oh) animals were divided in to two groups. In the suture IN group, both sutures were left in place from $\mathrm{Oh}$ and onwards, while in the suture OUT group, both sutures were removed at the $\mathrm{Oh}$ time point. In both groups animals were examined at $24 \mathrm{~h}, 72 \mathrm{~h}$ and $120 \mathrm{~h}$ time points by in vivo examination methods. In addition, animals were sampled at each time point to harvest tissue for laboratory analysis. Microarray analysis was performed in the naïve, $0 \mathrm{~h}$, and at $24 \mathrm{~h}$ in both the suture IN and suture OUT groups. The gene expression data was compared between $0 \mathrm{~h}, 24 \mathrm{~h}$ suture IN and $24 \mathrm{~h}$ suture OUT relative to the naïve cornea. In addition to the microarrays at $0 \mathrm{~h}$, whole-genome microarray analysis at $72 \mathrm{~h}$ and $120 \mathrm{~h}$ were the subject of a subsequent study focusing on time-dependent responses (Paper III).

Following removal of the angiogenic stimulus, an overall reduction in vascular density characterized the suture OUT group. In vivo confocal microscopy examination revealed a transition of the inflammatory cell response from granulocytes (appearing as hyper-reflective rounded and spindle-like cells ${ }^{34}$ ) to macrophage (large polymorphic with dark nucleus ${ }^{205}$ ) in the suture OUT group. The accumulating macrophages were of the M2 anti-angiogenic or remodeling phenotype (CD 204+). In addition, vessel splits (intussusception) increased with time in both suture IN and suture OUT groups. By immunohistochemistry analysis, removing the angiogenic stimuli delayed the deposition of basement membrane (Collagen IV) onto the newly formed capillaries. In 
general, the phenotypic characteristics described above were distinctly different between the suture IN and suture OUT groups at $72 \mathrm{~h}$ following suture removal. Based on this observation, it was reasoned that the genes regulating the observed phenotypic responses would be expressed starting at an earlier time, i.e. at the $24 \mathrm{~h}$ time point. In addition, preliminary gene expression analysis by qRTPCR showed suppression of Vegfa expression by $24 \mathrm{~h}$ after suture removal. With this in mind, whole transcriptome microarray analysis was performed at the $24 \mathrm{~h}$ time point in both groups. The resultant microarray data from the $24 \mathrm{~h}$ time points in both suture IN and suture OUT groups were normalized to that of the naïve cornea, to determine the differentially expressed genes for downstream analysis.

The analysis revealed an upregulation of pro-inflammatory mediators C-X-C Motif Chemokine Ligand 5 ( $\mathrm{Cxcl} 5)$, C-C motif chemokine ligand 2 ( $\mathrm{Ccl} 2)$, Serpin Family B Member 2 (Serpinb2), S100 calcium-binding protein A8 (S100a8) among others, in sutured corneas actively undergoing angiogenic sprouting. Removal of the sutures led to suppression of these genes in the suture OUT group, compared to the suture IN group. For instance, Cxcl5 was the most suppressed gene with a 41.7 fold change difference between suture IN and suture OUT at 24h. Genes such as Reg3g, Krt16, Ccl2 and Serpinb2, had a fold change difference of 24.8, 19.28, 15.6, and 15.18 respectively, between suture IN and suture OUT. These genes are mostly associated with inflammation. Among other genes, Vegfa was suppressed with suture removal, but to a more modest level with a fold change difference of 2.3. On the other hand, genes such as RAS p21 protein activator 2 (Rasa2), slit guidance ligand 2 (Slit2), CYLD lysine 63 deubiquitinase (Cyld) and glycogen synthase kinase 3 beta (Gsk3b) were upregulated in the suture OUT group, and were down regulated in the suture IN group. Comparing suture IN and suture OUT, the fold change difference between suture IN and suture OUT was 2.82, 2.56, 2.55, and 2.23 for Clyd, Slit2, Rasa2 and Gsk3b respectively. Remodeling and inhibition of angiogenesis generally had a much weaker effect than inflammation and active angiogenesis, at the gene expression level.

Taken together, results indicated that capillary remodeling stabilized some of the newly formed capillaries, suppressed granulocyte infiltration, promoted the accumulation of M2 macrophages and decreased the overall vascular density. This response was potentially mediated by the suppression of pro-inflammatory mediators such as $\mathrm{Cxcl} 5$, $\mathrm{Ccl} 2$, and Serpinb2, and at the same time an upregulation of putative capillary pro- 
remodeling genes such as Slit2, Rasa2, Gsk3b and Cyld (Fig.6). A detailed description of these results can be found in Papers I \& II.

\section{Suture IN}

-Up regulation of proangiogenic/proinflamatory genes

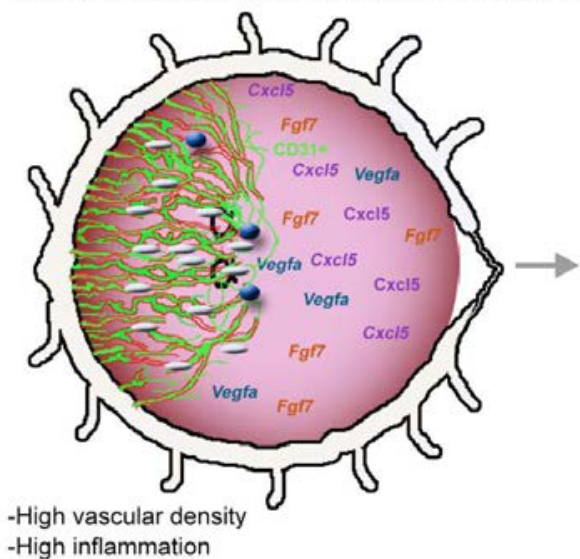

Suture OUT

-Up regulation of vessel promaturation genes

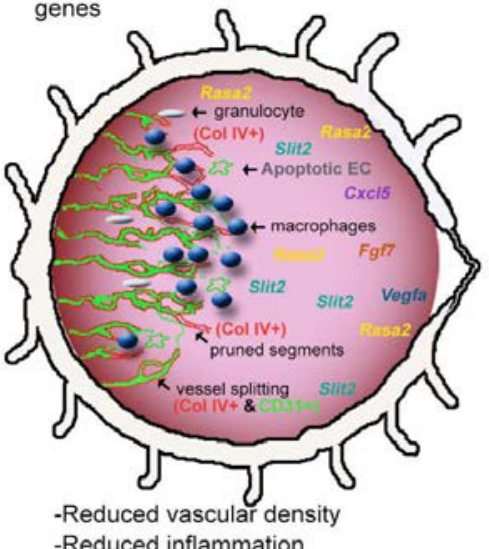

Figure 6. Graphical summary of capillary remodeling and regression in inflammatory corneal angiogenesis. Suture OUT represents a cornea where capillary remodeling was induced by suture removal, while suture IN represents a cornea where sutures were left in place for continued angiogenic stimulation, to serve as a control for the suture OUT group. The color coding of the genes is only for easy identification. (See Papers I \& II).

\subsubsection{LXR/RXR activation suppresses corneal inflammation time dependently (PAPER III)}

Capillary remodeling described in Papers I \& II above is associated with the timedependent resolution of inflammation. This resolving of inflammation may promote the establishment of functional and persistent capillary networks in the cornea. Regulation of the resolution of inflammation has not been investigated in detail previously, but could reveal mechanisms important for the establishment of persistent corneal vessels, as potential therapeutic targets. To investigate these mechanisms, the suture model of inflammatory corneal angiogenesis was used as described above. In brief, after four days of sprouting following suture placement, the angiogenic stimulus (sutures) were removed to induce capillary remodeling and regression, with this experimental group labelled as the 'remodeling arm'. In the parallel group termed the 'sprouting arm', both sutures were left in place after the four days of sprouting to provide constant angiogenic stimulation. As in Paper I, the sprouting arm (suture IN) served as a positive control for the remodeling arm (suture OUT). Animals in both arms were examined at $24 \mathrm{~h}, 72 \mathrm{~h}$ 
and at $120 \mathrm{~h}$. Whole transcriptome analysis was performed using microarrays (GeneChip RatGene 2.0 ST arrays) at $0 \mathrm{~h}, 24 \mathrm{~h}, 72 \mathrm{~h}$ and at $120 \mathrm{~h}$ time points. The $0 \mathrm{~h}$ time point was used to normalize the microarray data from the other time points (Fig. 7).

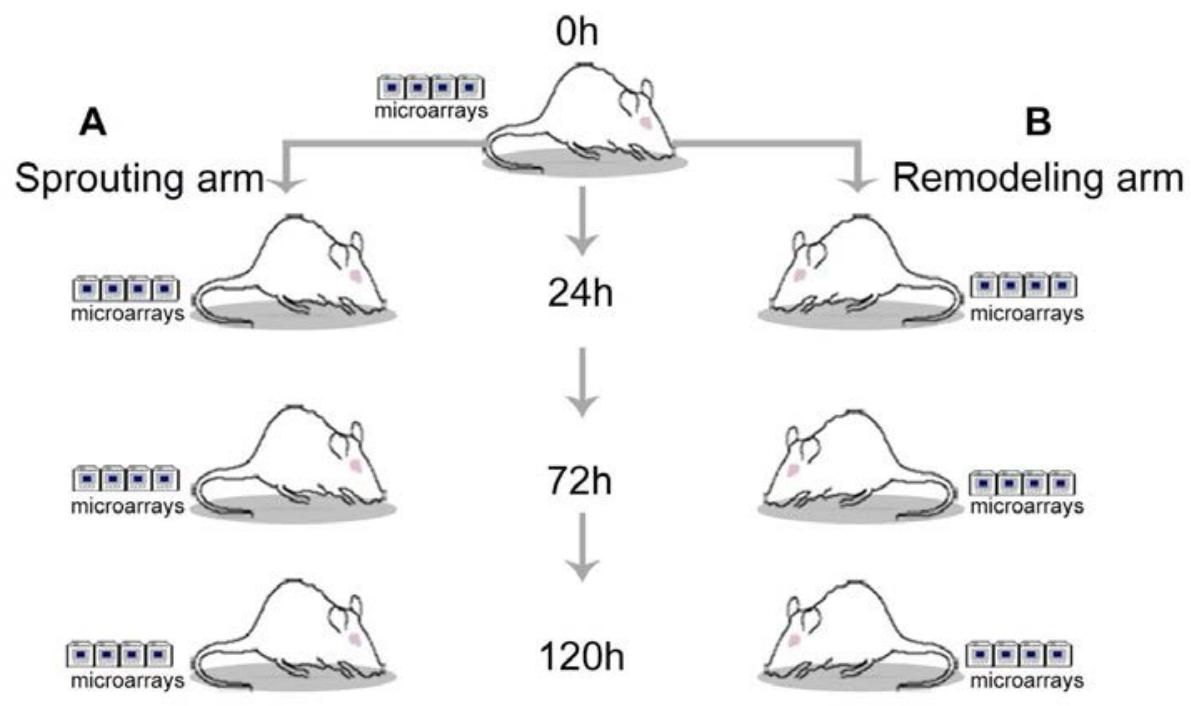

Figure 7. The experimental design used to investigate the time-dependent resolution of inflammation in the cornea. Two sutures were placed into the cornea and sprouting was allowed to proceed for four days. On the fourth day, $(\mathrm{Oh})$ animals were divided in to two groups. In the one group, both sutures were left in place from the $0 \mathrm{~h}$, through to the $120 \mathrm{~h}$ time point (referred to as the sprouting arm). In another group, both sutures were removed at the $0 \mathrm{~h}$ time point, and animals examined at $24 \mathrm{~h}, 72 \mathrm{~h}$ and $120 \mathrm{~h}$ time points (referred to as the remodeling arm). In addition to the in vivo examination, animals in both arms were sampled at each time point to harvest tissue for laboratory analysis by microarray. The number of microarray chips used for analysis is indicated beside each schematic representation of the rat, with no pooling of samples. The above experimental design was similar to that used in Papers I \& II, but with additional microarrays performed at 72 and $120 \mathrm{~h}$, and the data from these time points were normalised to data previously generated at the $0 \mathrm{~h}$ time in the first study (Paper I).

From analysis of the corneal response in vivo, removal of the angiogenic stimulus led to regression of capillaries characterized by a time-dependent vasoconstriction. Resolution of inflammation was indicated by the progressive absence of granulocytes, and appearance of macrophages in the cornea, maintaining the trend observed in the early stages of capillary remodeling as shown Paper I. Hierarchical cluster analysis of the microarray data indicated sample partitioning with time and with treatment.

Focusing on the remodeling arm, removal of the angiogenic stimulus led to an immediate inhibition of pathways such as VEGF ligand signaling, Jak/stat and ERK5 
signaling, Endothelin-1 signaling and IL6 signaling, at 24h - pathways that are strongly associated with promoting inflammation and angiogenesis.

At $72 \mathrm{~h}$, pathway inhibition continued, with interferon signaling being the most inhibited pathway with inhibition z-score of -2.5 , while Wnt $\beta$-catenin was the least inhibited with inhibition z-score of -1.5. The pathways LXR/RXR activation, STAT3 and Dendritic cell maturation were on the other hand activated to a comparable extent. Of note, $L X R / R X R$ activation in the remodeling arm was contrary to the inhibition status of the same pathway observed in the sprouting arm at $72 \mathrm{~h}$, highlighting a differential activation/suppression pattern between the two arms.

At $120 \mathrm{~h}$ in the remodeling arm, LPS/IL-1 inhibition of RXR function, and Wnt/betacatenin were persistently inhibited, maintaining an inhibition profile observed at both $24 \mathrm{~h}$ and $72 \mathrm{~h}$ time points during remodeling. In addition, pathways STAT3 and $\mathrm{LXR} / \mathrm{RXR}$ were still active at $120 \mathrm{~h}$, with an even higher activation z-score. For example, LXR/RXR activation increased from 1 to $1.8 \mathrm{z}$-score between $72 \mathrm{~h}$ and $120 \mathrm{~h}$, indicating a time-dependent activation. In addition, PPAR signaling was also activated at $120 \mathrm{~h}$.

Given the differential activation and time dependence of LXR described above, this pathway was analyzed in detail in the remodeling arm. By immunohistochemistry analysis, LXR a and LXR $\beta$ proteins were expressed by CD45+, CD68+ and by CD163+ cells (M2 remodeling macrophages), and in addition, their target genes ApoE and Abca1 were upregulated, and also expressed by CD68+ and CD163+ cells.

Taken together, the results indicated that resolution of inflammation in the cornea involves an early-phase inhibition of pro-inflammatory and pro-angiogenic pathways like VEGF ligand signaling, and in a later-phase, activation of anti-inflammatory pathways such as LXR/RXR and PPAR signaling. The activated anti-inflammatory pathways upregulate the expression of their target genes in this case such as ApoE and Abca1 in remodeling macrophages. This presumably promotes cholesterol transport out of these cells, leading to improved macrophage function in remodeling capillaries and suppressing the expression of pro-inflammatory genes such as $\mathrm{Ccl} 2$, IL-1 $\beta$ and IL-6 (Fig.8). A detailed description of these results can be found in Paper III. 


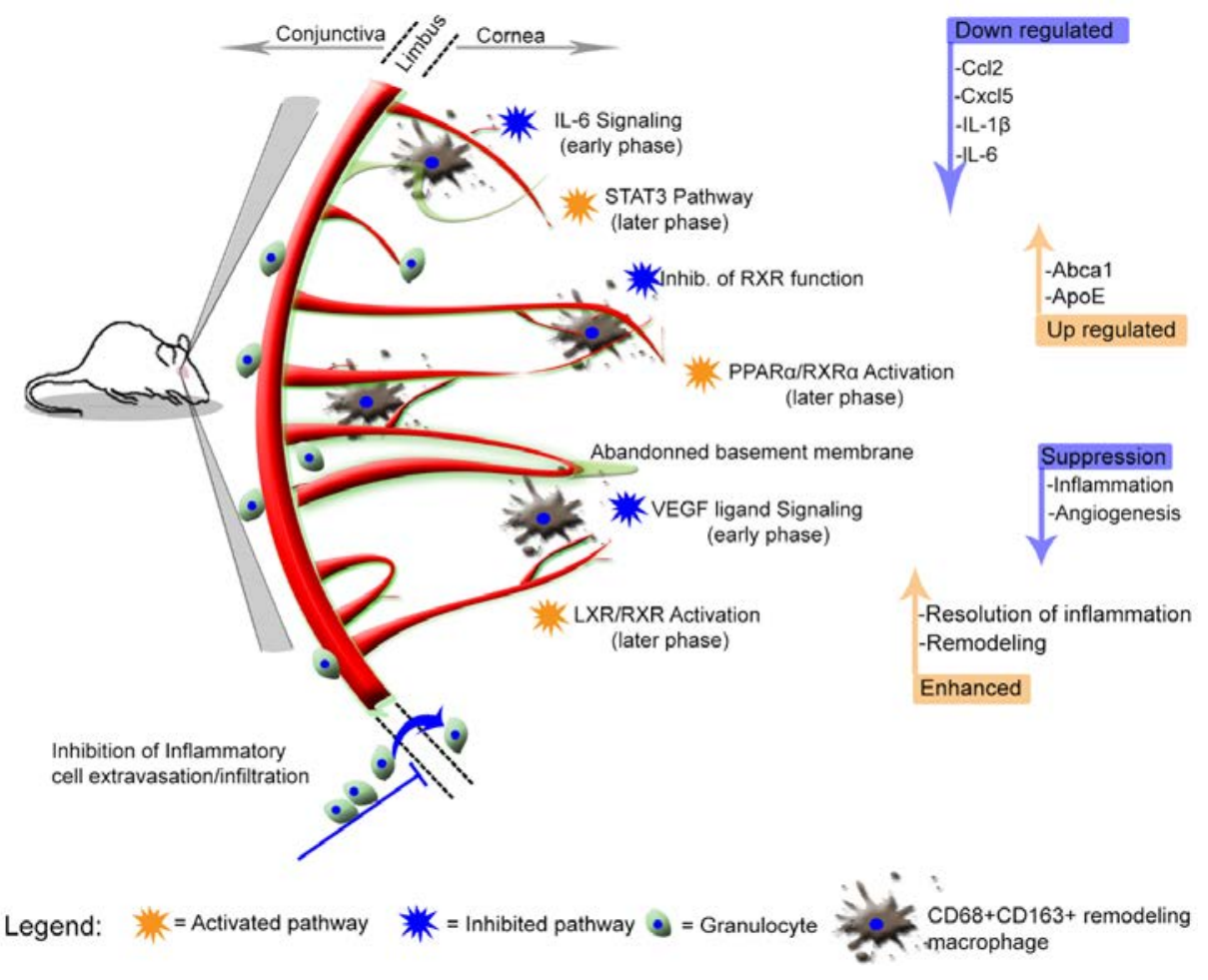

Figure 8. Graphical summary of the time-dependent resolution of inflammatory corneal angiogenesis, highlighting the cells, pathways and genes involved along with their activation/expression status. An early-phase inhibition of pro-inflammatory and pro-angiogenic pathways such as VEGF ligand signaling, II-6 signaling, and inhibition of RXR function, and a later-phase activation of anti-inflammatory pathways such as LXR/RXR , STAT3 pathways and PPAR signaling, was noted. Pro-inflammatory mediators such as $\mathrm{Ccl} 2, \mathrm{Cxcl} 5$, and IL-1 $\beta$, IL-6 were suppressed, and target genes for LXR activation ApoE and Abca1 were upregulated. (See Paper III).

\subsubsection{Ghost vessels facilitate rapid corneal revascularization (PAPER IV)}

The regression of capillaries along with resolution of inflammation described in Papers I - III, results in the formation of ghost vessels and empty basement membrane sleeves in the cornea. Ghost vessels are thought to be the remnants of previously perfused angiogenic capillaries in the cornea, and have been observed clinically in patients; however, little is known beyond their existence in the cornea. Empty basement membrane sleeves are structures observed in tissues after vessel/capillary regression, where previous functional and perfused vessels have lost their vascular endothelium and flow, leaving only the bare basement membrane tubes (sleeves) present $90,206,207,208$. To investigate the characteristics and role of ghost vessels and empty 
basement membrane sleeves during a corneal revascularization response, the suture model of inflammatory corneal angiogenesis was again used. Here, the model was used as described above, but with slight modifications. Briefly, corneal neovascularization was induced using two sutures. Sprouting of the newly formed capillaries was allowed for seven days (instead of four days as in Papers I - III). This modification was made to enable sprouting over a longer distance (at seven days the new sprouts reach the sutures), and allows time for the new capillaries to partially stabilize, to better mimic the clinical situation of corneal neovascularization. On the seventh day, sutures were removed to induce capillary regression over a thirty-day period. On the thirty-seventh day, the same cornea was re-sutured with two sutures (0h time point), and the animals were subsequently examined at $24 \mathrm{~h}, 72 \mathrm{~h}$ and $96 \mathrm{~h}$ (Fig.9). Whole transcriptome analysis was performed using microarrays (GeneChip RatGene 2.0 ST arrays) at 96h after re-suture.

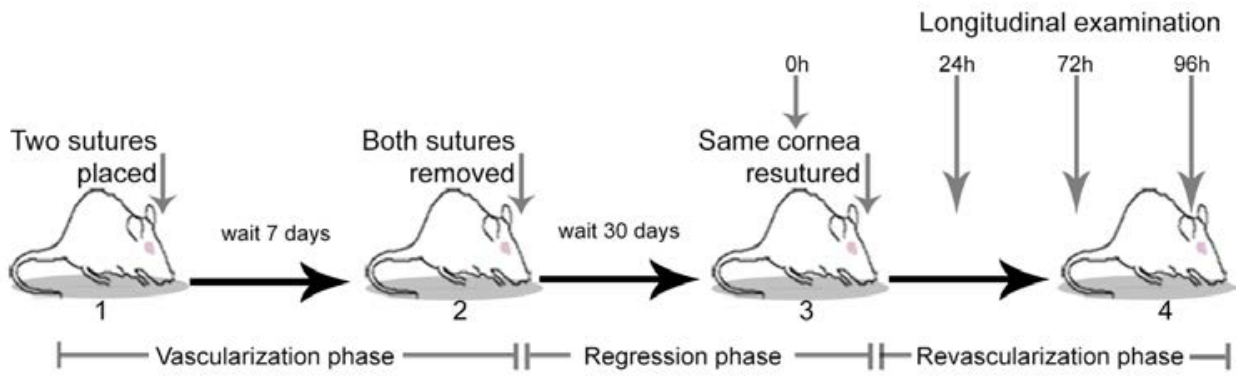

Figure 9. The experimental design used to investigate the role of ghost vessels and empty basement membrane sleeves in revascularization of the cornea. 1. Two sutures are placed into the cornea at $1.5 \mathrm{~mm}$ from the limbus and sprouting occurs for seven days. 2 . On the seventh day, sutures are removed to induce capillary regression over a thirty-day period. 3. After 30 days of regression, the same cornea is re-sutured $(\mathrm{Oh})$ and the animals are examined at $24 \mathrm{~h}, 72 \mathrm{~h}$ and $96 \mathrm{~h}$. 4, At 96h, animals are euthanized and corneal tissue is collected for laboratory analysis.

Regression of capillaries over a thirty-day period resulted in the formation of both ghost vessels and empty basement membrane sleeves. Here, we differentiate these two phenotypic structures by in vivo observation by IVCM, ex vivo observation by immunohistochemistry and by TEM analysis of the tissue. The main difference is that ghost vessels, although severely constricted, are still functional, possess vascular endothelium and have minimal blood/plasma flow (often permitting only single erythrocyte flow within the lumen), while basement membrane sleeves do not possess vascular endothelium or flow. TEM analysis of the ghost vessels revealed, however, 
that the endothelium of ghost vessels was abnormal, characterized by partial endothelial cell detachment from the basement membrane, microvilli-like projections into the capillary lumen, partial collapse of the capillary lumen, and with single erythrocytes flowing within the collapsing capillary wall.

Upon re-suture of the cornea with this regressed capillary bed, the ghost vessels became rapidly reperfused with blood. TEM analysis of the reperfusing vessels showed a greatly expanded vascular lumen with tightly packed erythrocytes, and with a normalized, functional vascular endothelial cell phenotype lining the re-perfused vessel wall. Endothelial cells were characterized by numerous cytoplasmic mitochondria, and were bordered by pericytes and by basement membrane on the external side of the capillary wall.

In comparison to the primary neovascularization response at 96h, corneal revascularization was of a much stronger magnitude, as illustrated by extensive dilation of capillaries and increased numbers of inflammatory cells infiltrating the cornea. Sprouting of new capillaries occurred at the front of the re-perfused capillaries, and were prominent by $96 \mathrm{~h}$ after re-suture. The empty basement membrane sleeves were not reused during the revascularization process. This was illustrated by an overall reduction in vascular density of the revascularized cornea compared to the vascular density of the same cornea on day 7 (prior to the induced regression). Furthermore, a side-by-side comparison of slit lamp images of the same cornea at day 7 , and at 96 of revascularization showed that many of the initial capillaries that regressed were not reperfused.

At the whole transcriptome level of analysis, an upregulation of pro-inflammatory mediators such as $\mathrm{Ccl} 2, \mathrm{Ccl} 6, \mathrm{IL}-1 \beta$, and IL-6 was associated with revascularization. In comparison to the initial angiogenic phase, these genes were on average 20 -fold upregulated during revascularization. Pathway enrichment analysis revealed activation of pro-inflammatory pathways such as production of nitric oxide and reactive oxygen species and ILK signaling, and at the same time, inhibition of anti-inflammatory pathways such as LXR/RXR signaling. Genes IL-6, IL-1 $\beta$ and Vegfa are examples of upstream regulators for the pathways enriched in the revascularization phase.

Taken together, the results indicate that a revascularization response is robust and more severe than the initial angiogenesis, in terms of phenotype and gene expression. 
This may be attributed to persistent ghost vessels in the cornea, which are functional and maintain at least a single cell flow, and are composed of a degenerate vascular endothelium. The vascular endothelium of ghost vessels is characterized by loosely attached endothelial cells with multiple microvilli-like projections into the capillary lumen. Upon re-suture, the ghost vessel endothelium rapidly normalizes while the capillary lumen dilates significantly and refills with a strong flow of blood. Sprouting of new capillaries occurs at the front of the re-perfused capillaries and not through reactivation of basement membrane sleeves or repopulation of such sleeves with vascular endothelial cells, as has been suggested in other models ${ }^{209}$. Activation of proinflammatory pathways such as production of nitric oxide and reactive oxygen species signaling, and at the same time inhibition of anti-inflammatory pathway such as LXR/RXR signaling, may explain the observed hyper dilation. (Fig.10). A detailed description of these results can be found in Paper IV.

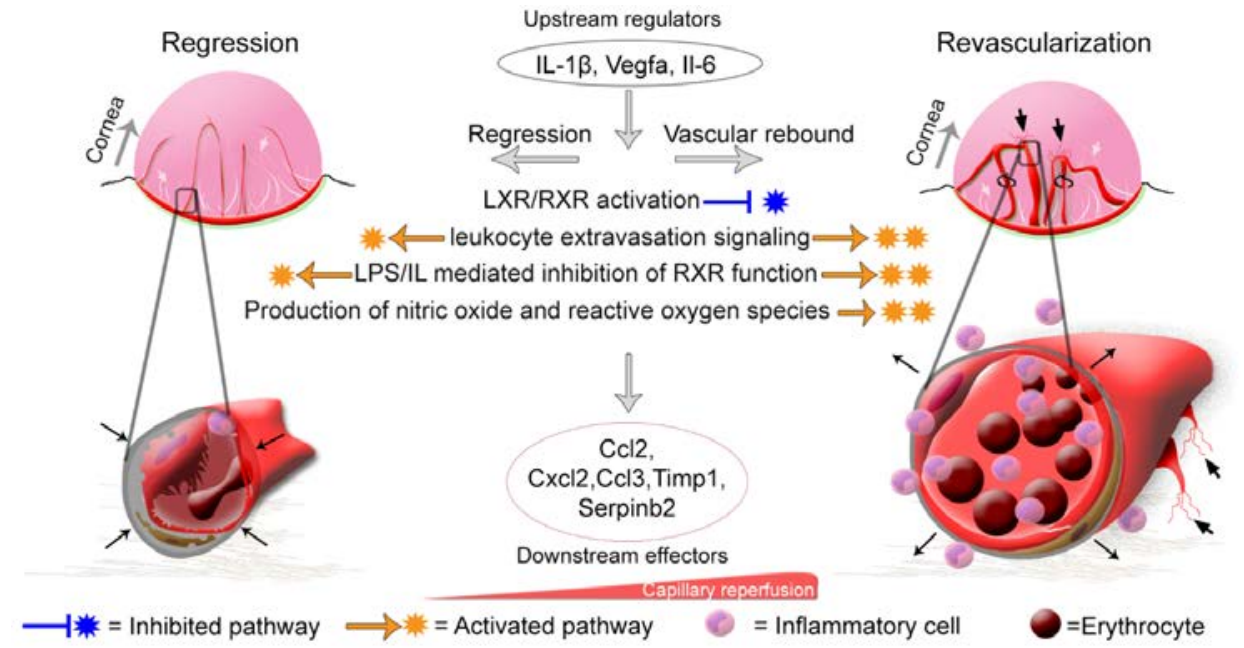

Number of stars $=$ degree of inhibition/activation, and no star $=$ no activity status information

$\nwarrow$ Pointing into the capillary represents capillary collapse $\downarrow$ Pointing away from the capillary represents dilation

Figure 10. Summary of events characterizing the regression and the revascularization response of the cornea to a repeated stimulus. Revascularization of the cornea was associated with the activation of pro-inflammatory pathways such as leukocyte extravasation, LPS/IL-1 mediated inhibition of RXR function, and production of nitric oxide and reactive oxygen species, indicated by orange color arrows and stars. At the same time, the anti-inflammatory pathway LXR/RXR activation was inhibited, indicated by the blue colored lines above. Activated upstream regulators for the observed pathway enrichment include IL-1ß, Vegfa and IL-6. Pro-inflammatory mediators such as Ccl2, Ccl3, Cxcl2 and Serpinb2 (referred to in the above as 'downstream effectors') were upregulated. Sprouting occurred at the front of the re-perfused vessels. (See Paper IV). 


\subsubsection{Corticosteroid treatment suppresses pro-inflammatory genes and activates complement component factors (PAPERS V \& VI)}

Corticosteroids are effective in resolving ocular inflammation, but with their use comes associated side effects. Understanding the differential mode of action of steroids in comparison to more specific anti-neovascularization treatments could help identify alternative treatment targets for treating corneal neovascularization, that avoid the broad activity of steroids but may mimic their suppressive effects. To address this, the suture model of inflammatory corneal angiogenesis was used as described above but with some modifications. Here, following suture placement, eye drops (IgG, anti-Vegf and dexamethasone) were given to the sutured cornea 4 times per day for two days. On the second day (48h), rats were examined in vivo before tissue was harvested for analysis using GeneChip Rat 2302.0 microarrays. Different from the study designs described above, here the early inflammatory response in a pre-sprouting phase (48h) was investigated, to better understand the mode of action of steroids in an early phase not complicated by active sprouting (Fig.11).

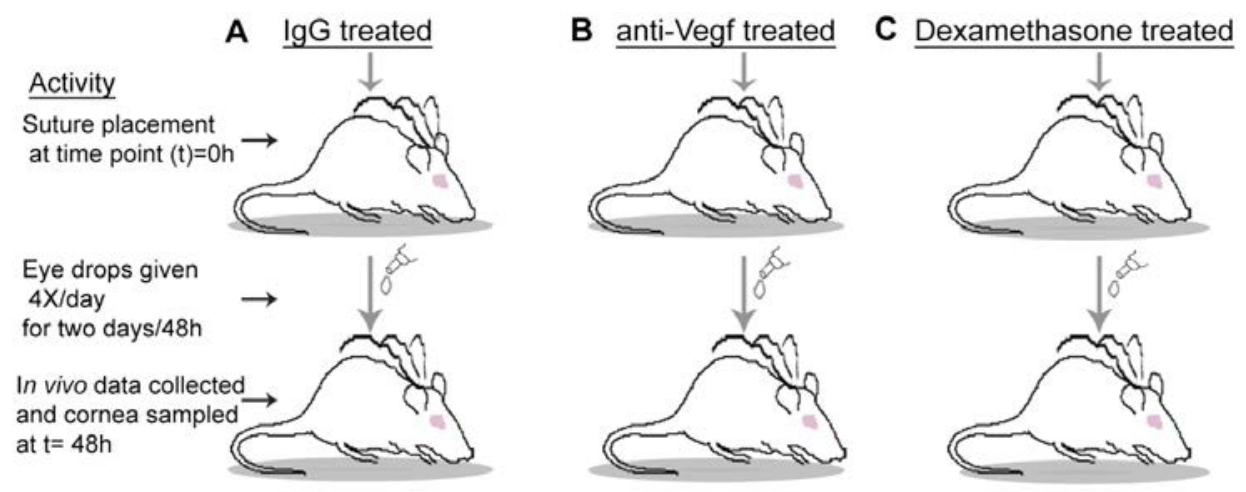

Figure 11. The experimental design used to investigate the differential effect of steroids and anti-Vegf in treating corneal neovascularization. Two sutures were placed into the cornea at $1.5 \mathrm{~mm}$ from the limbus. The sutured rats where divided into three groups corresponding to topical treatment with $\lg G$ $(A)$, anti-Vegf (B) or dexamethasone (C). Animals were treated four times per day for two days. After the second day (48h), animals were examined in vivo and corneal tissue was harvested for laboratory analysis.

From in vivo analysis, capillary dilation as an early indicator of inflammation preceding sprouting angiogenesis in this model was suppressed by dexamethasone treatment relative to the IgG treated group. On the contrary, anti-Vegf treatment did not suppress early limbal vasodilation relative to the IgG-treated group. In comparison to the anti- 
Vegf treated group, dexamethasone treatment suppressed vasodilation by a 5 -fold magnitude. Early inflammatory cell infiltration into the cornea at $5 \mathrm{~h}$ post-suture, as another inflammatory indicator, was not suppressed by any of the treatments.

At the whole transcriptome level of analysis, dexamethasone treatment suppressed expression of pro-inflammatory genes such as $\mathrm{Ccl} 2$ and $\mathrm{Cxcl} 5$ by 40 and 8-fold, respectively, relative to anti-Vegf treatment. Contrary to the suppression of proinflammatory mediators, dexamethasone treatment promoted the upregulation of complement C3 (C3), complement C1s (C1s), C2, and other classical complement pathway factors relative to anti-Vegf treatment. In addition, genes such as complement factor I (Cfi), a complement inhibitor, was suppressed by dexamethasone treatment, relative to anti-Vegf and lgG treatments.

Taken together, the results indicated that steroid treatment in the cornea suppresses the expression of potent pro-inflammatory genes such as $\mathrm{Cxcl} 5$ and $\mathrm{Ccl} 2$ to subdue inflammation in an early phase. In addition, steroid treatment promotes activation of the classical complement system by activating classical complement factors and inhibiting the expression of Cfi, thereby enhancing synthesis of $\mathrm{C} 3$ and $\mathrm{C} 5$, by $\mathrm{C} 3$ and C5 convertase respectively, leading to enhanced inflammatory cell infiltration (Fig.12). A detailed description of these results can be found in Papers $\mathrm{V} \& \mathrm{VI}$.

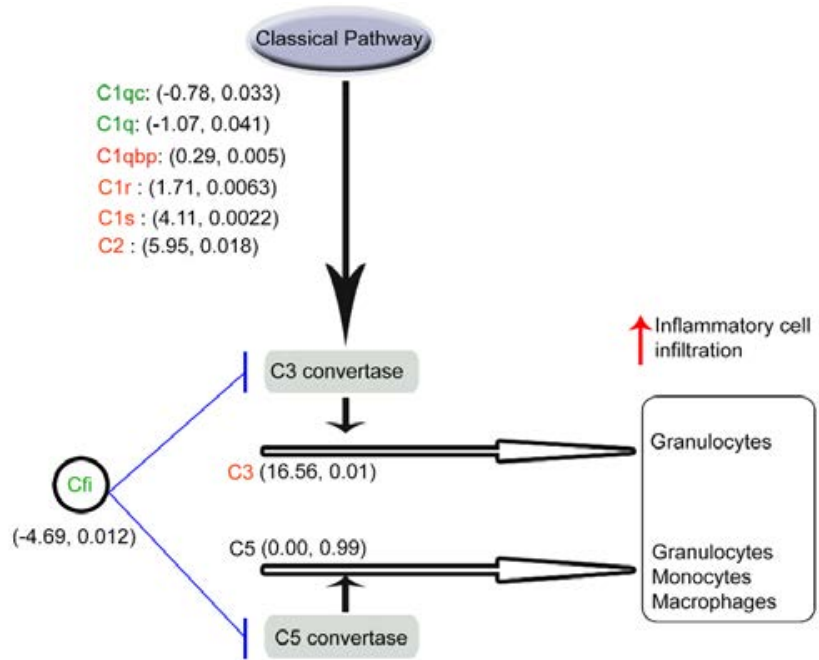

Figure 12. Graphical summary (adapted from del Zoppo ${ }^{210}$ ) of the proposed mode of action of steroids in activating the classical complement pathway. The represented genes were differentially regulated by dexamethasone relative to the anti-Vegf treatment in the cornea model. Upregulated genes are shown 
in red color, while down regulated genes are shown in green color. The difference in fold change i.e. (fold change dexamethasone minus fold change anti-Vegf) is shown in parentheses, along with the corresponding $p$-value. The differentially expressed genes activate the classical complement pathway, leading to C3 upregulation, which in turn promotes inflammatory cell infiltration into the cornea. (See Papers V \& VI). 


\subsection{Discussion and future aspects}

The lack of effective treatments against corneal neovascularization presents a major clinical challenge. Currently, corticosteroids are used to treat corneal angiogenesis but the side effects associated with steroid use ${ }^{211}$ need to be addressed if these are to be safely used for this purpose. Anti-VEGF treatments on the other hand are used offlabel in the cornea, and are of limited efficacy $71,178,212,179,213,214$. The drawbacks of both steroids and anti-VEGF warrants the need for safer and more effective treatments. The search for alternative treatment approaches and targets $78,215,216,217,218$, and ways to circumvent resistance to treatment is underway. One of the hypothesized means of resistance to anti-VEGF treatment is by the rapid remodeling and maturation of capillaries, making them less susceptible to treatment. Pro-remodeling/maturation genes such as Cyld, Slit2, Rasa2 and Gsk3b identified here, as being upregulated during the remodeling response are potential mediators of capillary remodeling. In line with this, Slit2/roundabout (Robo) signaling axis has been shown to regulate vascular remodeling in other systems ${ }^{219}$. Slit2 was shown to impair VEGF-induced tumor angiogenesis ${ }^{220}$. In corneal angiogenesis, Slit2 was shown to interact with Robo 1 and Robo 4 to impair neovascularization ${ }^{221}$. Slit2 in other conditions is shown to have anti-inflammatory properties ${ }^{222}$. The differential upregulation of Slit2 in remodeling capillaries observed here corroborates these reports. Therefore, Slit2 and the other pro-remodeling/maturations genes identified here warrant further investigation as targets to inhibit capillary remodeling, to keep the newly formed capillaries immature and hence more susceptible to treatment.

The remodeling capillaries here were associated with the accumulation of $\mathrm{M} 2$ macrophages (CD204+ and CD163+), which likely mediate anti-inflammatory properties, given that M2 macrophages have previously been reported to have antiinflammatory properties 223,224,225. However, macrophages are key inflammatory mediators and are of variable plasticity $226,227,228$. Some studies have shown M2 macrophages promoting angiogenesis 229,230,231. In addition, proper cholesterol transport from macrophages is important for their functionality. Impairment of this process can lead to pathological vascular proliferation due to the accumulation of cholesterol within the cell resulting in an abnormal macrophage phenotype ${ }^{232}$. Therefore, the role of the M2 macrophage population might be tissue- and diseasespecific. 
Initial capillary remodeling is associated with attenuation of inflammation over time in the cornea ${ }^{233}$. The longitudinal whole transcriptome analysis of the time dependent resolution of inflammation in the cornea revealed inhibition of proangiogenic pathways such as VEGF signaling ${ }^{234}$, and at the same time, activation of anti-inflammatory pathways such as LXR/RXR signaling ${ }^{235}$. This balance between pro and anti-inflammatory pathways is intriguing, as it provides clues to the regulation of inflammation in this model system. Not surprisingly, LXRs are known to mediate anti-inflammatory properties $236,237,238,239,240$. LXRs mediate their antiinflammatory properties by transrepression of NF-KB-signaling $241,240,242$, a pathway known to be involved in corneal neovascularization $77,78,243$. It is probable that LXRs suppresses inflammation in the cornea through transrepression of NF-KB-signaling, as reported in other conditions ${ }^{244}$. In addition, the expression of LXR target genes Abca1 245 and ApoE 246 by corneal macrophages, is in line with the reported activity of LXRs in this cell type $235,247,248$. If LXR agonists are to be adopted for use in the cornea, their associated side effects such as hypertriglyceridemia and hepatic steatosis ${ }^{249}$ will need to be circumvented. However, on a positive note, reports are emerging with means to reduce these effects. For instance, site-specific antibody delivery of LXR agonist is shown to localize treatment, hence reducing the undesired side effects ${ }^{250}$. For the corneal indications, it is inevitable to think of LXR formulations in the form of eye drops, to localize their effects and minimize undesired side effects. This route of treatment administration is continuously being improved to further reduce undesirable side effects ${ }^{251}$. However, the efficacy of LXR agonists in suppressing inflammation in the cornea remains to be evaluated.

Even where capillary regression is apparent and treatment of corneal neovascularization is successful, extensive remodeling and regression of capillaries and the time-dependent resolution of inflammation results in the formation of ghost vessels and empty basement membrane sleeves 233,252,253. These features are distinguished here as separate structures with differing characteristics. The ultrastructure of corneal ghost vessels revealed that they contain an endothelium, however, the endothelium was rather in a degenerative state. The ghost vessels were characterized by endothelial cell detachment from the basement membrane, by collapse of the capillary lumen, and multiple projections of microvilli-like processes into the capillary lumen from the endothelial cells. These ghost vessels often had single erythrocyte flow. These characteristics are potential indicators of 
regressing vessels, as reported previously ${ }^{254}$. The characteristics of ghost vessels observed here were of particular interest, given that ghost vessels were previously thought to be non-functional ${ }^{255,256,257}$, to have no vascular endothelium ${ }^{258,259,260}$, and to be non-perfused 261,262 . The definition of ghost vessels could be tissue and disease specific, or may be confused with empty basement membrane sleeves in other studies that do not use the cornea as a model. In other models, such as in tumor models ${ }^{209}$, it is difficult or impossible to image such structures in vivo, to observe their perfusion status, and to examine the same structures longitudinally to determine their fate during revascularization. The revascularization response was robust and quicker compared to the initial angiogenic response, and this is probably due to some sort of immunological priming and memory of the cornea.

Extensive vasodilation during revascularization is likely to be a result of the activation of nitric oxide (NO) and reactive oxygen species (ROS) signaling. In line with this, previous reports have implicated ROS in vasodilation, vascular permeability 263,264 , and in the activity of matrix metalloproteinases ${ }^{265}$. Re-perfusion of capillaries may have induced shear stress activation of endothelial cell ${ }^{266}$ to promote their rapid normalization, reactivation and survival. In addition, the numerous mitochondria observed in the endothelial cells might be responsible for the activation of ROS, since mitochondria in endothelial cells are known to mediate ROS signaling ${ }^{267}$. Besides ROS, LXR/RXR signaling was inhibited during revascularization, which illustrates the potential importance of inflammation in the response, given that LXR/RXR activation was recently shown to have anti-inflammatory properties in the cornea (Paper III). Revascularization of the cornea by re-perfusion of the ghost vessels, and not the empty basement membrane sleeves contradicts previous reports that showed that empty basement membrane sleeves can serve as scaffolds for the reforming vessels ${ }^{209}$. However, attempts to degrade empty base basement membrane sleeves to slow down revascularization were futile ${ }^{268}$. From our current understanding, it is possible that the empty basement membrane sleeves were not principally reused during revascularization in that study, but rather it was the ghost vessels that facilitated this process. The limiting factor of testing this hypothesis in other models will be the inaccessibility of the experimental site for a longitudinal in vivo examination making it impossible to follow capillaries before and after revascularization. Such drawbacks of other models leave the cornea, and the suture 
model of inflammatory corneal angiogenesis as very useful tools for further investigation to answer questions such as: Are the re-perfused capillaries susceptible to antiangiogenic therapies? Do anti-angiogenic treatments influence the manner of capillary regression, and future revascularization? Addressing these questions could for instance provide information with clinical relevance in cases where there is a high risk of revascularization of the cornea due to incomplete eradication of the angiogenic or inflammatory stimulus. In another context, the model mimics the situation of reactivation of tumors after the initial regression of angiogenic capillaries due to acquired treatment resistance or cessation of anti-angiogenic therapy. Persistent ghost vessels may therefore represent an important treatment target in the cancer setting ${ }^{209}$.

To maintain the efficacy of corticosteroids while minimizing their side effects 269,270 is another treatment strategy for inflammatory corneal neovascularization, which is under investigation ${ }^{71}$. It is hypothesized that by identifying the most efficient targets for steroids, these can then be selectively targeted for effective results with less or no side effects. Here, it was found that in addition to suppressing the expression of pro-inflammatory genes such as $\mathrm{Cxcl} 5$ and $\mathrm{Ccl} 2$, steroid use seemed to activate complement, specifically upregulating complement $\mathrm{C} 2, \mathrm{C} 3$ and $\mathrm{C} 1 \mathrm{~s}$, to potentially suppress angiogenesis. In support of this idea, activation of complement specifically C5a-C5aR has been shown to inhibit angiogenesis in a model of retinopathy of prematurity (ROP) ${ }^{271}$, and some studies in tumor angiogenesis have also shown inhibitory effects of complement system in angiogenesis ${ }^{272}$. However, the complement system should be approached with caution, because it has the capacity to both defend against invading pathogens, and at the same time to inflict tissue damage 273,274 . In addition, complement activation has been observed in the pathogenesis of retinal diseases such as in AMD 275,276,277. The findings here could also imply that classical complement pathway seems to be important in cornea while the alternative pathway seems to be more important in the retina. More generally, targeting inflammation, for instance by inhibiting factors such as $\mathrm{Cxcl} 5$ and/or $\mathrm{Ccl} 2$ would be an interesting approach to investigate as a potential supplement to antiVEGF therapy. 


\subsection{Conclusions}

The search for safer and more effective treatments against corneal neovascularization is an ongoing process, and the work presented here generates new knowledge regarding the regulation of inflammation and angiogenesis, highlighting the role of previously unidentified pathways and genes in this model system. Therefore, we concluded that;

1. Keeping the newly formed capillaries in an immature state, hence susceptible to treatment may be further investigated by focusing on pro-remodeling genes such as Slit2, Rasa2 and Cyld, and at the same time by suppressing pro-inflammatory mediators such as $\mathrm{Cxcl} 5$ and $\mathrm{Ccl} 2$, among others, to suppress inflammatory corneal angiogenesis.

2. $L X R / R X R$ signaling and $P P A R \alpha / R X R \alpha$ pathways are activated with time in the cornea to subdue inflammation. The anti-inflammatory property of $L X R / R X R$ is at least partially mediated by tissue macrophages, leading to the suppression of proinflammatory mediators such as $\mathrm{Ccl} 2, \mathrm{Cxcl} 5, \mathrm{II} 1 \beta$, and $I 16$.

3. Ghost vessels and not empty basement membrane sleeves facilitate corneal revascularization. The revascularization response is a rapid process characterized by vasodilation, inflammatory cell infiltration and by sprouting at the front of the reperfused capillaries. The response is also more severe compared to the initial angiogenesis. Activation of pro-inflammatory pathways such ROS and nitrous oxide signaling, and at the same time inhibition of anti-inflammatory pathways such as $\mathrm{LXR/RXR}$ signaling, are potential regulatory mechanisms for this response.

4. Activation of the classical complement pathway, and at the same time suppression of pro-inflammatory genes such as $\mathrm{Cxcl} 5$ and $\mathrm{Ccl} 2$, is a potential mode of action of corticosteroids to suppress inflammatory corneal angiogenesis, effects that are not achieved with anti-VEGF treatment. 


\section{ACKNOWLEDGEMENTS}

Many people have been a great part of this journey, and I would like to express my gratitude towards them. Special thanks to;

Neil Lagali my main supervisor, for granting me the opportunity to undertake the Ph.D. training under your supervision. The past few years have been very exciting and such an amazing experience, enriched with stimulating scientific discussions and meetings, both at the local and international level. Thanks for all these opportunities, as they were such a revelation. You were always there to attend to matters, even in difficult times for example the late night emails, or the time you had a fractured arm, but still addressed project matters. That was humbling! Thank you for tolerating the occasional impromptu meetings, which ensured a smooth running of project activities. Amidst your clinical responsibilities, you always made time for experiments, thank you! Thank you for granting me the freedom to dream and be creative at all levels of the projects, from this, I learned a lot. Thank you for the overall mentorship process; it has been a very wonderful journey.

Beatrice Bourghardt Peebo my co-supervisor, for guiding me through the practicalities of the suture-model of inflammatory corneal angiogenesis, and for the insights in ocular angiogenesis in general. You always encouraged me, recounting your own Ph.D. experience, which inspired and kept me motivated. Our discussions were very encouraging and such a wonderful experience. You kept me in balance by reminding me of the other aspects of life. Amidst your busy clinical schedule, you always made time for experiments, and for group meetings. You worked late to ensure a smooth running of project activities. Tack för att du gav mig inspiration att lära mig svenska! Jag ska fortsätta träna! Thank you for being a wonderful co-supervisor.

Lasse Jensen my co-supervisor, for inspiring the journal club meetings. Your presentations were both inspirational and humbling. From you, I learned that there is always room for improvement, and that it is not over until it is over! :-) The challenges you brought forth always seemed impossible at the beginning, but in addressing them, a lot was learned, ideas were born, and the overall experience enriched my imagination and creativity. Thank you for always being there whenever I come running with questions - . Your passion for top-notch science is amazing, and very inspiring. Along with the great science is your wonderful sense of humour, you are always full of energy, 
and most importantly, you pass it on to others! Thank you for being an inspirational cosupervisor.

Per Fagerholm, for laying the foundation for basic eye research at the eye clinic. It is because of your effort that work such as this was possible. Thank you for your role in all the other scientific duties associated with this work.

Zaheer Ali, for helping me to find my way around LiU in the very beginning of this journey. Thank you for the demonstrations of the zebrafish model of angiogenesis, and for the times you covered my back especially when conducting hypoxia experiments. Thank you for being my study buddy during Swedish language lessons, and for being very cooperative when it mattered most, especially on those conference trips and visits to Boston, New York, Baltimore and in Guangzhou. I know you will never forget the phrase 'help me to help you';:! All the best with the remaining journey of your studies kompis!

Anton Lennikov, for your contribution in the faster establishment the laboratory which enabled us accomplish projects in a much shorter time span. Thank you for your help with the experiments, and for the inspiration in adopting the rodent aortic ring assay. Thank you for the inspiration, support, advice, and for the scientific discussions we held, regarding theoretical and laboratory methods, and scientific theories. It was fun! They were only two, but very productive years!

Pierfrancesco Mirabelli, for the scientific discussions, and for help with animal experiments, despite your busy clinical schedule.

Maria Xeroudaki, for the assistance with the animal experiments and for the insightful discussions during the journal club meetings. Your contribution helped lay the foundation for this work and is very much appreciated.

Maria Ntzouni, for your contribution and technical support with TEM.

Caroline Fluur, who made possible Papers I-III, and for your interest in this work.

Jessica Lindvall, for the assistance with the bioinformatics during the early phase of this journey. 
Muthukumar Thangavelu, for the encouraging words and for the help with the experiments. I know handling those 'animals' was not always fun, but believe me, you did great!

Mira Schaupper and Mieszko Lachota, it was nice working with you both. You were always full of energy and inspiring.

Mehdi Amirhosseini, for the support and encouraging words. All the best with your upcoming thesis defence.

Johanna Huoman, for the support, great cooperation and making sure we had a seminar room booked for the course assignments and discussions. I wish you the very best with your studies.

Annelie Lindström and Gunilla Linghammar, for the continuous administrative support and advice regarding my studies.

Monica Johansson, for the administrative support all through these years.

Annette Dellby, for making sure we had all that we needed for animal experiments, including sterilization of the surgical equipment, and restocking the supplies like syringes and anesthetics. You made life a lot easier, thank you.

Catharina Traneus Röckert and Camilla Hildesjö for technical support and help with immunohistochemistry.

Maria Falck Miniotis, for the encouragement throughout the years.

Marina Koulikovska, for the great advice, and encouraging words.

Staff at CBR2, for support with managing animal orders, and for keeping an eye on the animals during experimentation.

Madeleine Marie from IMH, for being supportive in granting me access to $\mathrm{IMH}$, where some of the experiments were conducted.

The entire IKE department, especially the staff of the division of Ophthalmology including doctors and nurses, for the meetings and for an overall smooth stay throughout the study period. 
The Ph.D. thesis committee, the examination board (Xiao-Feng Sun, Jesper Hjortdal, Maria Jenmalm and Jan Ernerudh), and the faculty opponent (Thomas Ritter), for taking part in this journey.

To my family:

Joan my dearest, thank you for all the support, patience, encouragement and generally keeping me sane during this journey. This work would not have been possible if you had not signed up for it as well.

My wonderful boys Jeremy and Jaden, yes, you are too little to understand a thing, but just know that you both were a good distraction. Attending to your (endless:) needs always rejuvenated me, and got me fired up for the next day at work. Sorry that you sometimes got a 'Not now, daddy is busy', response.

My beloved parents, for laying the foundation right from my childhood and for instilling in me the basic values of life needed to accomplish tasks like this.

Brothers and sisters Joseph, Francis, Henry, Paul, Emma, Goretti, Prossy, Florence, for being supportive and encouraging in different aspects, hence making all this journey possible.

My parents-in-law, for the endless support over the years especially the period just before, and during this journey.

Janefrances for dropping by when we needed it the most, to keep the work going. To Jose and Jue, for being very supportive in so many different ways.

To my other friends:

And last but not least to my friends scattered all over the world especially Gerald, Andrew, Ruhollah, Mike, Sydney, Emma, Sudeep, Alfred, John, Barnabas, Peter, Reza, Joseph, Ronnie, to name but a few, thank you for the encouraging words and support over the years. I hope you now understand why I may have been lost and acting weird:).

Funding: By the Swedish Research Council (Grant No. 2012-2472) and an unrestricted basic research grant from Bayer HealthCare AB, Solna, Sweden. 


\section{REFERENCES}

1 Ramrattan, R. S. et al. Prevalence and causes of visual field loss in the elderly and associations with impairment in daily functioning: the Rotterdam Study. Archives of Ophthalmology 119, 1788-1794 (2001).

2 McCarty, C. A., Nanjan, M. B. \& Taylor, H. R. Vision impairment predicts 5 year mortality. British Journal of Ophthalmology 85, 322-326 (2001).

3 Eckert, K. A. et al. A simple method for estimating the economic cost of productivity loss due to blindness and moderate to severe visual impairment. Ophthalmic epidemiology 22, 349-355 (2015).

4 Bourne, R. R. et al. Magnitude, temporal trends, and projections of the global prevalence of blindness and distance and near vision impairment: a systematic review and meta-analysis. The Lancet Global Health 5, e888-e897 (2017).

5 Whitcher, J. P., Srinivasan, M. \& Upadhyay, M. P. Corneal blindness: a global perspective. Bulletin of the World Health Organization 79, 214-221 (2001).

6 Thylefors, B. Epidemiological patterns of ocular trauma. Clinical \& Experimental Ophthalmology 20, 95-98 (1992).

7 Thylefors, B. Present challenges in the global prevention of blindness. Clinical \& Experimental Ophthalmology 20, 89-94 (1992).

8 Taylor, K. I. \& Taylor, H. R. Distribution of azithromycin for the treatment of trachoma. British journal of ophthalmology 83, 134-135 (1999).

9 Copeland, R. A., Afshari, N. A. \& Dohlman, C. H. Copeland and Afshari's Principles and Practice of Cornea. Vol. 1 (JP Medical Ltd, 2013).

10 Cox, J., Farrell, R., Hart, R. \& Langham, M. The transparency of the mammalian cornea. The Journal of physiology 210, 601-616 (1970).

11 Quantock, A. J. \& Young, R. D. Development of the corneal stroma, and the collagenproteoglycan associations that help define its structure and function. Developmental Dynamics 237, 2607-2621 (2008).

12 Hertsenberg, A. J. \& Funderburgh, J. L. in Progress in molecular biology and translational science Vol. 134 25-41 (Elsevier, 2015).

13 Ambati, B. K. et al. Corneal avascularity is due to soluble VEGF receptor-1. Nature 443, 993 (2006).

14 Ramaesh, T. et al. Corneal abnormalities in Pax6+/- small eye mice mimic human aniridiarelated keratopathy. Investigative ophthalmology \& visual science 44, 1871-1878 (2003).

15 Schedl, A. et al. Influence of PAX6 gene dosage on development: overexpression causes severe eye abnormalities. Cell 86, 71-82 (1996).

16 Jordan, T. et al. The human PAX6 gene is mutated in two patients with aniridia. Nature genetics 1, 328 (1992).

17 Cursiefen, C. et al. Roles of thrombospondin-1 and-2 in regulating corneal and iris angiogenesis. Investigative ophthalmology \& visual science 45, 1117-1124 (2004).

18 Hiscott, P., Seitz, B., Schlötzer-Schrehardt, U. \& Naumann, G. O. Immunolocalisation of thrombospondin 1 in human, bovine and rabbit cornea. Cell and tissue research 289, 307-310 (1997).

19 Lawler, J. Thrombospondin-1 as an endogenous inhibitor of angiogenesis and tumor growth. Journal of cellular and molecular medicine 6, 1-12 (2002).

20 Lawler, J. The functions of thrombospondin-1 and-2. Current opinion in cell biology 12, 634640 (2000).

21 Lin, H.-C. et al. Matrilysin cleavage of corneal collagen type XVIII NC1 domain and generation of a 28-kDa fragment. Investigative ophthalmology \& visual science 42, 2517-2524 (2001).

Ogata, N. et al. Expression of pigment epithelium-derived factor in normal adult rat eye and experimental choroidal neovascularization. Investigative ophthalmology \& visual science 43, 1168-1175 (2002). 
Azar, D. T. Corneal angiogenic privilege: angiogenic and antiangiogenic factors in corneal avascularity, vasculogenesis, and wound healing (an American Ophthalmological Society thesis). Transactions of the American Ophthalmological Society 104, 264 (2006). Risau, W. in Collateral Circulation 17-28 (Springer, 1992).

Mancuso, M. R., Kuhnert, F. \& Kuo, C. J. Developmental angiogenesis of the central nervous system. Lymphatic research and biology 6, 173-180 (2008).

Pierce, E. A., Foley, E. D. \& Smith, L. E. Regulation of vascular endothelial growth factor by oxygen in a model of retinopathy of prematurity. Archives of ophthalmology 114, 1219-1228 (1996).

Stone, J. et al. Development of retinal vasculature is mediated by hypoxia-induced vascular endothelial growth factor (VEGF) expression by neuroglia. Journal of Neuroscience 15, 47384747 (1995).

Rouhi, P. et al. Hypoxia-induced metastasis model in embryonic zebrafish. Nature protocols $\mathbf{5}$, 1911 (2010).

Shi, Y.-H. \& Fang, W.-G. Hypoxia-inducible factor-1 in tumour angiogenesis. World journal of gastroenterology 10, 1082 (2004).

Chouaib, S. et al. Hypoxia promotes tumor growth in linking angiogenesis to immune escape. Frontiers in immunology 3, 21 (2012).

Lin, C., McGough, R., Aswad, B., Block, J. A. \& Terek, R. Hypoxia induces HIF-1 $\alpha$ and VEGF expression in chondrosarcoma cells and chondrocytes. Journal of Orthopaedic Research 22, 1175-1181 (2004).

Hernández, C. \& Simó, R. Strategies for blocking angiogenesis in diabetic retinopathy: from basic science to clinical practice. Expert opinion on investigational drugs 16, 1209-1226 (2007).

Arjamaa, O. \& Nikinmaa, M. Oxygen-dependent diseases in the retina: role of hypoxiainducible factors. Experimental eye research 83, 473-483 (2006).

Peebo, B. B., Fagerholm, P., Traneus-Röckert, C. \& Lagali, N. Time-lapse in vivo imaging of corneal angiogenesis: the role of inflammatory cells in capillary sprouting. Investigative ophthalmology \& visual science 52, 3060-3068 (2011).

Amano, S., Rohan, R., Kuroki, M., Tolentino, M. \& Adamis, A. P. Requirement for vascular endothelial growth factor in wound-and inflammation-related corneal neovascularization. Investigative ophthalmology \& visual science 39, 18-22 (1998). Risau, W. Mechanisms of angiogenesis. Nature 386, 671 (1997).

Werb, Z., Vu, T. H., Rinkenberger, J. L. \& Coussens, L. M. Matrix-degrading proteases and angiogenesis during development and tumor formation. Apmis 107, 11-18 (1999).

Phng, L.-K., Stanchi, F. \& Gerhardt, H. Filopodia are dispensable for endothelial tip cell guidance. Development 140, 4031-4040 (2013).

Gerhardt, H. et al. VEGF guides angiogenic sprouting utilizing endothelial tip cell filopodia. The Journal of cell biology 161, 1163-1177 (2003).

Iruela-Arispe, M. L. \& Davis, G. E. Cellular and molecular mechanisms of vascular lumen formation. Developmental cell 16, 222-231 (2009).

Dejana, E., Tournier-Lasserve, E. \& Weinstein, B. M. The control of vascular integrity by endothelial cell junctions: molecular basis and pathological implications. Developmental cell 16, 209-221 (2009).

Phng, L.-K. \& Gerhardt, H. Angiogenesis: a team effort coordinated by notch. Developmental cell 16, 196-208 (2009).

Hellström, M. et al. Dll4 signalling through Notch1 regulates formation of tip cells during angiogenesis. Nature 445, 776 (2007).

Lobov, I. et al. Delta-like ligand 4 (DII4) is induced by VEGF as a negative regulator of angiogenic sprouting. Proceedings of the National Academy of Sciences 104, 3219-3224 (2007).

Leslie, J. D. et al. Endothelial signalling by the Notch ligand Delta-like 4 restricts angiogenesis. Development 134, 839-844 (2007). 
Caduff, J., Fischer, L. \& Burri, P. H. Scanning electron microscope study of the developing microvasculature in the postnatal rat lung. The Anatomical Record 216, 154-164 (1986). Benest, A. V. \& Augustin, H. G. Tension in the vasculature. Nature medicine 15, 608 (2009). Styp-Rekowska, B., Hlushchuk, R., Pries, A. \& Djonov, V. Intussusceptive angiogenesis: pillars against the blood flow. Acta physiologica 202, 213-223 (2011).

Mukwaya, A. et al. Factors regulating capillary remodeling in a reversible model of inflammatory corneal angiogenesis. Scientific reports 6, 32137 (2016).

Springer, T. A. Traffic signals for lymphocyte recirculation and leukocyte emigration: the multistep paradigm. Cell 76, 301-314 (1994).

Han, Y.-P., Tuan, T.-L., Wu, H., Hughes, M. \& Garner, W. L. TNF-alpha stimulates activation of pro-MMP2 in human skin through NF-(kappa) B mediated induction of MT1-MMP. Journal of Cell Science 114, 131-139 (2001).

Imhof, B. A. \& Aurrand-Lions, M. Angiogenesis and inflammation face off. Nature medicine 12, $171(2006)$.

El Awad, B. et al. Hypoxia and interleukin-1 $\beta$ stimulate vascular endothelial growth factor production in human proximal tubular cells. Kidney international 58, 43-50 (2000).

Talghini, S. \& Shenasi, A. Concomitant examination of inflammation and angiogenesis in the pathogenesis of primary moderate pterygium in a well-designed case-control study. Pakistan journal of biological sciences: PJBS 16, 1046-1050 (2013).

Capitão, M. \& Soares, R. Angiogenesis and inflammation crosstalk in diabetic retinopathy. Journal of cellular biochemistry 117, 2443-2453 (2016).

Campa, C. et al. Inflammatory mediators and angiogenic factors in choroidal neovascularization: pathogenetic interactions and therapeutic implications. Mediators of inflammation 2010 (2010).

Mueller, M. in Tumor angiogenesis 351-362 (Springer, 2008).

Ribatti, D. in Inflammation and Angiogenesis 25-26 (Springer International Publishing, 2017). Lee, P., Wang, C. C. \& Adamis, A. P. Ocular neovascularization: an epidemiologic review. Survey of ophthalmology 43, 245-269 (1998).

60 Klintworth, G. K. in Corneal Angiogenesis 4-4 (Springer, 1991).

61 Maddula, S., Davis, D. K., Maddula, S., Burrow, M. K. \& Ambati, B. K. Horizons in therapy for corneal angiogenesis. Ophthalmology 118, 591-599 (2011).

Azher, T. N., Yin, X.-T. \& Stuart, P. M. Understanding the role of chemokines and cytokines in experimental models of herpes simplex keratitis. Journal of immunology research 2017 (2017). Chang, S. W., Chuang, J. L. \& Chou, S. F. Mechanical corneal epithelium scraping and ethanol treatment up-regulate cytokine gene expression differently in rabbit cornea. Journal of Refractive Surgery 24, 150-159 (2008).

Fukuda, K., Ishida, W., Miura, Y., Kishimoto, T. \& Fukushima, A. Cytokine expression and barrier disruption in human corneal epithelial cells induced by alarmin released from necrotic cells. Japanese Journal of Ophthalmology 61, 415-422 (2017).

Nakao, S. et al. Dexamethasone inhibits interleukin-1ß-induced corneal neovascularization: role of nuclear factor-kB-activated stromal cells in inflammatory angiogenesis. The American journal of pathology 171, 1058-1065 (2007).

Goede, V., Brogelli, L., Ziche, M. \& Augustin, H. G. Induction of inflammatory angiogenesis by monocyte chemoattractant protein-1. International Journal of Cancer 82, 765-770 (1999). polymorphonuclear neutrophils recruitment during corneal infection in mice. Immunology and cell biology 85, 525 (2007).

Tandon, A., Tovey, J. C., Sharma, A., Gupta, R. \& Mohan, R. R. Role of transforming growth factor Beta in corneal function, biology and pathology. Current molecular medicine 10, 565578 (2010).

Wisse, R. P. et al. Cytokine expression in keratoconus and its corneal microenvironment: a systematic review. The ocular surface 13, 272-283 (2015). 

(2005).

71 Mirabelli, P., Peebo, B. B., Xeroudaki, M., Koulikovska, M. \& Lagali, N. Early effects of dexamethasone and anti-VEGF therapy in an inflammatory corneal neovascularization model. Experimental eye research 125, 118-127 (2014).

Shaw, S. K. et al. Coordinated redistribution of leukocyte LFA-1 and endothelial cell ICAM-1 accompany neutrophil transmigration. Journal of Experimental Medicine 200, 1571-1580 (2004).

Barreiro, O. et al. Dynamic interaction of VCAM-1 and ICAM-1 with moesin and ezrin in a novel endothelial docking structure for adherent leukocytes. The Journal of cell biology 157, 12331245 (2002).

KVANTA, A., SARMAN, S., FAGERHOLM, P., SEREGARD, S. \& STEEN, B. Expression of matrix metalloproteinase-2 (MMP-2) and vascular endothelial growth factor (VEGF) in inflammationassociated corneal neovascularization. Experimental eye research 70, 419-428 (2000).

Lee, S., Zheng, M., Kim, B. \& Rouse, B. T. Role of matrix metalloproteinase-9 in angiogenesis caused by ocular infection with herpes simplex virus. The Journal of clinical investigation 110, 1105 (2002).

Marrazzo, G. et al. The role of neutrophils in corneal wound healing in HO-2 null mice. PLoS One 6, e21180 (2011).

Lan, W., Petznick, A., Heryati, S., Rifada, M. \& Tong, L. Nuclear Factor-kB: central regulator in ocular surface inflammation and diseases. The ocular surface 10, 137-148 (2012).

Lennikov, A. et al. Selective IKK2 inhibitor IMD0354 disrupts NF-KB signaling to suppress corneal inflammation and angiogenesis. Angiogenesis, 1-19 (2018).

Peebo, B. B., Fagerholm, P., Traneus-Röckert, C. \& Lagali, N. Cellular-level characterization of lymph vessels in live, unlabeled corneas by in vivo confocal microscopy. Investigative ophthalmology \& visual science 51, 830-835 (2010).

81 Maruyama, K. et al. Inflammation-induced lymphangiogenesis in the cornea arises from CD11b-positive macrophages. The Journal of clinical investigation 115, 2363-2372 (2005).

Cursiefen, C. et al. Lymphatic vessels in vascularized human corneas: immunohistochemical investigation using LYVE-1 and podoplanin. Investigative ophthalmology \& visual science 43, 2127-2135 (2002).

Cursiefen, C., Chen, L., Dana, M. R. \& Streilein, J. W. Corneal lymphangiogenesis: evidence, mechanisms, and implications for corneal transplant immunology. Cornea 22, 273-281 (2003). Yamagami, S., Dana, M. R. \& Tsuru, T. Draining lymph nodes play an essential role in alloimmunity generated in response to high-risk corneal transplantation. Cornea 21, 405-409 (2002).

Medzhitov, R. Toll-like receptors and innate immunity. Nature Reviews Immunology 1, 135 (2001).

Bolaños-Jiménez, R. et al. Ocular surface as barrier of innate immunity. The open ophthalmology journal 9, 49 (2015).

Tabeta, K. et al. Toll-like receptors 9 and 3 as essential components of innate immune defense against mouse cytomegalovirus infection. Proc. Natl. Acad. Sci. U. S. A. 101, 3516-3521 (2004).

Dieu, M.-C. et al. Selective recruitment of immature and mature dendritic cells by distinct chemokines expressed in different anatomic sites. Journal of Experimental Medicine 188, 373386 (1998). Ausprunk, D. The sequence of events in the regression of corneal capillaries. Lab Invest 38, 284-294 (1978).

91 Bergers, G. \& Hanahan, D. Modes of resistance to anti-angiogenic therapy. Nature Reviews Cancer 8, 592 (2008). 

pericytes and endothelial cells in the tumor vasculature with kinase inhibitors. The Journal of clinical investigation 111, 1287-1295 (2003).

Helfrich, I. \& Schadendorf, D. Blood vessel maturation, vascular phenotype and angiogenic potential in malignant melanoma: One step forward for overcoming anti-angiogenic drug resistance? Molecular oncology 5, 137-149 (2011).

94 Potente, M., Gerhardt, H. \& Carmeliet, P. Basic and therapeutic aspects of angiogenesis. Cell 146, 873-887 (2011).

95 Franco, C. A. et al. Dynamic endothelial cell rearrangements drive developmental vessel regression. PLoS biology 13, e1002125 (2015).

96 Hughes, S. \& Chan-Ling, T. Roles of endothelial cell migration and apoptosis in vascular remodeling during development of the central nervous system. Microcirculation 7, 317-333 (2000).

97 Modlich, U., Kaup, F.-J. \& Augustin, H. G. Cyclic angiogenesis and blood vessel regression in the ovary: blood vessel regression during luteolysis involves endothelial cell detachment and vessel occlusion. Laboratory investigation; a journal of technical methods and pathology 74, 771-780 (1996).

98 Mitchell, C. A., Risau, W. \& Drexler, H. C. Regression of vessels in the tunica vasculosa lentis is initiated by coordinated endothelial apoptosis: a role for vascular endothelial growth factor as a survival factor for endothelium. Developmental dynamics 213, 322-333 (1998).

99 Lang, R., Lustig, M., Francois, F., Sellinger, M. \& Plesken, H. Apoptosis during macrophagedependent ocular tissue remodelling. Development 120, 3395-3403 (1994).

100 Meeson, A., Palmer, M., Calfon, M. \& Lang, R. A relationship between apoptosis and flow during programmed capillary regression is revealed by vital analysis. Development $\mathbf{1 2 2}$, 39293938 (1996).

101 Meeson, A. P., Argilla, M., Ko, K., Witte, L. \& Lang, R. A. VEGF deprivation-induced apoptosis is a component of programmed capillary regression. Development 126, 1407-1415 (1999).

102 Chen, Q. et al. Haemodynamics-driven developmental pruning of brain vasculature in zebrafish. PLoS biology 10, e1001374 (2012).

103 Dekker, R. J. et al. Endothelial KLF2 links local arterial shear stress levels to the expression of vascular tone-regulating genes. The American journal of pathology 167, 609-618 (2005).

104 Baffert, F. et al. Cellular changes in normal blood capillaries undergoing regression after inhibition of VEGF signaling. American Journal of Physiology-Heart and Circulatory Physiology 290, H547-H559 (2006).

105 Baluk, P. et al. Regulated angiogenesis and vascular regression in mice overexpressing vascular endothelial growth factor in airways. The American journal of pathology 165, 1071-1085 (2004).

106 Clevers, H. \& Nusse, R. Wnt/ $\beta$-catenin signaling and disease. Cell 149, 1192-1205 (2012).

107 Augustin, H. G., Koh, G. Y., Thurston, G. \& Alitalo, K. Control of vascular morphogenesis and homeostasis through the angiopoietin-Tie system. Nature reviews Molecular cell biology 10, 165 (2009).

108 Zhang, F. et al. VEGF-B is dispensable for blood vessel growth but critical for their survival, and VEGF-B targeting inhibits pathological angiogenesis. Proceedings of the National Academy of Sciences 106, 6152-6157 (2009).

109 Liang, D. et al. The role of vascular endothelial growth factor (VEGF) in vasculogenesis, angiogenesis, and hematopoiesis in zebrafish development. Mechanisms of development 108, 29-43 (2001).

110 Harper, S. J. \& Bates, D. O. VEGF-A splicing: the key to anti-angiogenic therapeutics? Nature Reviews Cancer 8, 880-887 (2008).

111 Woolard, J., Harper, S. J. \& Bates, D. O. Molecular diversity of VEGF-A as a regulator of its biological activity. Microcirculation 16, 572-592 (2009). 
112 Ferrara, N., Houck, K. A., Jakeman, L. B., Winer, J. \& Leung, D. W. The vascular endothelial growth factor family of polypeptides. Journal of cellular biochemistry 47, 211-218 (1991).

113 Leung, D. W., Cachianes, G., Kuang, W.-J., Goeddel, D. V. \& Ferrara, N. Vascular endothelial growth factor is a secreted angiogenic mitogen. Science 246, 1306 (1989).

114 Tischer, E. et al. Vascular endothelial growth factor: a new member of the platelet-derived growth factor gene family. Biochemical and biophysical research communications 165, 11981206 (1989).

115 Houck, K. A. et al. The vascular endothelial growth factor family: identification of a fourth molecular species and characterization of alternative splicing of RNA. Molecular endocrinology 5, 1806-1814 (1991).

116 Poltorak, Z. et al. VEGF145, a secreted vascular endothelial growth factor isoform that binds to extracellular matrix. Journal of Biological Chemistry 272, 7151-7158 (1997).

117 Park, J. E., Keller, G.-A. \& Ferrara, N. The vascular endothelial growth factor (VEGF) isoforms: differential deposition into the subepithelial extracellular matrix and bioactivity of extracellular matrix-bound VEGF. Molecular biology of the cell 4, 1317-1326 (1993).

118 Keyt, B. A. et al. The carboxyl-terminal domain (111165) of vascular endothelial growth factor is critical for its mitogenic potency. Journal of Biological Chemistry 271, 7788-7795 (1996).

119 Carmeliet, P. et al. Abnormal blood vessel development and lethality in embryos lacking a single VEGF allele. Nature 380, 435 (1996).

120 Ferrara, N. et al. Heterozygous embryonic lethality induced by targeted inactivation of the VEGF gene. Nature 380, 439 (1996).

121 Koch, S., Tugues, S., Li, X., Gualandi, L. \& Claesson-Welsh, L. Signal transduction by vascular endothelial growth factor receptors. Biochemical journal 437, 169-183 (2011).

122 Abhinand, C. S., Raju, R., Soumya, S. J., Arya, P. S. \& Sudhakaran, P. R. VEGF-A/VEGFR2 signaling network in endothelial cells relevant to angiogenesis. Journal of cell communication and signaling 10, 347-354 (2016).

123 Meissner, M. et al. Suppression of VEGFR2 expression in human endothelial cells by dimethylfumarate treatment: evidence for anti-angiogenic action. Journal of Investigative Dermatology 131, 1356-1364 (2011).

124 Cudmore, M. J. et al. The role of heterodimerization between VEGFR-1 and VEGFR-2 in the regulation of endothelial cell homeostasis. Nature communications 3, 972 (2012).

125 Waltenberger, J., Claesson-Welsh, L., Siegbahn, A., Shibuya, M. \& Heldin, C.-H. Different signal transduction properties of KDR and Flt1, two receptors for vascular endothelial growth factor. Journal of Biological Chemistry 269, 26988-26995 (1994).

126 Shibuya, M. Vascular endothelial growth factor receptor-1 (VEGFR-1/FIt-1): a dual regulator for angiogenesis. Angiogenesis 9, 225-230 (2006).

127 Shibuya, M. Vascular endothelial growth factor (VEGF) and its receptor (VEGFR) signaling in angiogenesis: a crucial target for anti-and pro-angiogenic therapies. Genes \& cancer 2, 10971105 (2011).

128 Heldin, C.-H. Dimerization of cell surface receptors in signal transduction. Cell 80, 213-223 (1995).

129 Kim, l. et al. Vascular endothelial growth factor expression of intercellular adhesion molecule 1 (ICAM-1), vascular cell adhesion molecule 1 (VCAM-1), and E-selectin through nuclear factorKB activation in endothelial cells. Journal of Biological Chemistry 276, 7614-7620 (2001).

130 Melder, R. et al. During angiogenesis, vascular endothelial growth factor and basic fibroblast growth factor regulate natural killer cell adhesion to tumor endothelium. Nature medicine $\mathbf{2}$, 992-997 (1996).

131 Scaldaferri, F. et al. VEGF-A links angiogenesis and inflammation in inflammatory bowel disease pathogenesis. Gastroenterology 136, 585-595. e585 (2009).

132 Barleon, B. et al. Migration of human monocytes in response to vascular endothelial growth factor (VEGF) is mediated via the VEGF receptor flt-1. Blood 87, 3336-3343 (1996). 
133 Massena, S. et al. Identification and characterization of VEGF-A-responsive neutrophils expressing CD49d, VEGFR1, and CXCR4 in mice and humans. Blood 126, 2016-2026 (2015).

134 Olofsson, B. et al. Vascular endothelial growth factor B (VEGF-B) binds to VEGF receptor-1 and regulates plasminogen activator activity in endothelial cells. Proceedings of the National Academy of Sciences 95, 11709-11714 (1998).

135 Olofsson, B. et al. Vascular endothelial growth factor B, a novel growth factor for endothelial cells. Proceedings of the National Academy of Sciences 93, 2576-2581 (1996).

136 Ortéga, N., Hutchings, H. \& Plouët, J. Signal relays in the VEGF system. Front Biosci 4, D141D152 (1999).

137 Scrofani, S. D., Fabri, L. J., Xu, P., Maccarone, P. \& Nash, A. D. Purification and refolding of vascular endothelial growth factor-B. Protein Science 9, 2018-2025 (2000).

138 Aase, K. et al. Vascular endothelial growth factor-B-deficient mice display an atrial conduction defect. Circulation 104, 358-364 (2001).

139 Bellomo, D. et al. Mice lacking the vascular endothelial growth factor-B gene (Vegfb) have smaller hearts, dysfunctional coronary vasculature, and impaired recovery from cardiac ischemia. Circulation research 86, e29-e35 (2000).

140 Jensen, L. D. et al. VEGF-B-Neuropilin-1 signaling is spatiotemporally indispensable for vascular and neuronal development in zebrafish. Proceedings of the National Academy of Sciences 112, E5944-E5953 (2015).

141 Shweiki, D., Itin, A., Soffer, D. \& Keshet, E. Vascular endothelial growth factor induced by hypoxia may mediate hypoxia-initiated angiogenesis. Nature 359, 843-845 (1992).

142 Sweat, R. S., Sloas, D. C. \& Murfee, W. L. VEGF-C induces lymphangiogenesis and angiogenesis in the rat mesentery culture model. Microcirculation 21, 532-540 (2014).

143 Karkkainen, M. J. et al. Vascular endothelial growth factor $C$ is required for sprouting of the first lymphatic vessels from embryonic veins. Nature immunology 5, 74 (2004).

144 Witzenbichler, B. et al. Vascular endothelial growth factor-C (VEGF-C/VEGF-2) promotes angiogenesis in the setting of tissue ischemia. The American journal of pathology 153, 381-394 (1998).

145 Wang, X., Zhao, J., Qin, L. \& Qiao, M. Promoting inflammatory lymphangiogenesis by vascular endothelial growth factor-C (VEGF-C) aggravated intestinal inflammation in mice with experimental acute colitis. Brazilian Journal of Medical and Biological Research 49 (2016).

146 Cha, H.-S. et al. Tumor necrosis factor-alpha induces vascular endothelial growth factor-C expression in rheumatoid synoviocytes. The Journal of rheumatology 34, 16-19 (2007).

147 Baer, J. C. \& Foster, C. S. Corneal laser photocoagulation for treatment of neovascularization: Efficacy of $577 \mathrm{~nm}$ yellow dye laser. Ophthalmology 99, 173-179 (1992).

148 Pillai, C. T., Dua, H. S. \& Hossain, P. Fine needle diathermy occlusion of corneal vessels. Investigative Ophthalmology \& Visual Science 41, 2148-2153 (2000).

149 Yoon, K.-C. et al. Photodynamic therapy with verteporfin for corneal neovascularization. American journal of ophthalmology 144, 390-395. e391 (2007).

150 Shakiba, Y., Mansouri, K., Arshadi, D. \& Rezaei, N. Corneal neovascularization: molecular events and therapeutic options. Recent patents on inflammation \& allergy drug discovery $\mathbf{3}$, 221-231 (2009).

151 Petroutsos, G., Guimaraes, R., Giraud, J. \& Pouliquen, Y. Corticosteroids and corneal epithelial wound healing. The British journal of ophthalmology 66, 705 (1982).

152 Tomas-Barberan, S. \& Fagerholm, P. Influence of topical treatment on epithelial wound healing and pain in the early postoperative period following photorefractive keratectomy. Acta Ophthalmologica 77, 135-138 (1999).

153 Gordon, M. et al. Phase I safety and pharmacokinetic study of recombinant human antivascular endothelial growth factor in patients with advanced cancer. Journal of Clinical Oncology 19, 843-850 (2001).

154 Krebs, l. et al. Efficacy of intravitreal bevacizumab (Avastin ${ }^{\circledR}$ ) therapy for early and advanced neovascular age-related macular degeneration. Acta ophthalmologica 87, 611-617 (2009). 
155 Ávila, M. P. et al. Three-year safety and visual acuity results of epimacular 90strontium/90yttrium brachytherapy with bevacizumab for the treatment of subfoveal choroidal neovascularization secondary to age-related macular degeneration. Retina 32, 1018 (2012).

156 Ahmed, A., Berati, H., Nalan, A. \& Aylin, S. Effect of bevacizumab on corneal neovascularization in experimental rabbit model. Clinical \& experimental ophthalmology 37, 730-736 (2009).

157 Koenig, Y. et al. Short-and long-term safety profile and efficacy of topical bevacizumab (Avastin ${ }^{\circledast}$ ) eye drops against corneal neovascularization. Graefe's Archive for Clinical and Experimental Ophthalmology 247, 1375-1382 (2009).

158 Kim, S. W., Ha, B. J., Kim, E. K. \& Tchah, H. The effect of topical bevacizumab on corneal neovascularization. Ophthalmology 115, e33-e38 (2008).

159 Chen, Y. et al. Selection and analysis of an optimized anti-VEGF antibody: crystal structure of an affinity-matured Fab in complex with antigen. Journal of molecular biology 293, 865-881 (1999).

160 Mordenti, J. et al. Comparisons of the intraocular tissue distribution, pharmacokinetics, and safety of 125I-labeled full-length and Fab antibodies in rhesus monkeys following intravitreal administration. Toxicologic pathology 27, 536-544 (1999).

161 Shahar, J. et al. Electrophysiologic and retinal penetration studies following intravitreal injection of bevacizumab (Avastin). Retina 26, 262-269 (2006).

162 Heiduschka, P. et al. Penetration of bevacizumab through the retina after intravitreal injection in the monkey. Investigative Ophthalmology \& Visual Science 48, 2814-2823 (2007).

163 Rosenfeld, P. J. et al. Ranibizumab for neovascular age-related macular degeneration. New England Journal of Medicine 355, 1419-1431 (2006).

164 Group, C. R. Ranibizumab and bevacizumab for neovascular age-related macular degeneration. New England Journal of Medicine 364, 1897-1908 (2011).

165 Schmucker, C. et al. A safety review and meta-analyses of bevacizumab and ranibizumab: offlabel versus goldstandard. PLoS One 7, e42701 (2012).

166 Hutton, D., Newman-Casey, P. A., Tavag, M., Zacks, D. \& Stein, J. Switching to less expensive blindness drug could save medicare part B $\$ 18$ billion over a ten-year period. Health Affairs 33, 931-939 (2014).

167 Gragoudas, E. S., Adamis, A. P., Cunningham Jr, E. T., Feinsod, M. \& Guyer, D. R. Pegaptanib for neovascular age-related macular degeneration. New england journal of medicine 351, 28052816 (2004).

168 Bagnasco, L. et al. Role of angiogenesis inhibitors in colorectal cancer: sensitive and insensitive tumors. Current cancer drug targets 12, 303-315 (2012).

169 Holash, J. et al. VEGF-Trap: a VEGF blocker with potent antitumor effects. Proceedings of the National Academy of Sciences 99, 11393-11398 (2002).

170 Stewart, M. W. et al. Pharmacokinetic rationale for dosing every 2 weeks versus 4 weeks with intravitreal ranibizumab, bevacizumab, and aflibercept (vascular endothelial growth factor Trap-eye). Retina 32, 434-457 (2012).

171 Dixon, J. A., Oliver, S. C., Olson, J. L. \& Mandava, N. VEGF Trap-Eye for the treatment of neovascular age-related macular degeneration. Expert opinion on investigational drugs 18, 1573-1580 (2009).

172 Avitabile, T. et al. Aflibercept in the Treatment of Diabetic Macular Edema: A Review and Consensus Paper. European journal of ophthalmology 27, 627-639 (2017).

173 Ozkaya, A., Tulu, B. \& Garip, R. Aflibercept in macular edema secondary to retinal vein occlusion: A real life study. Saudi Journal of Ophthalmology 31, 211-215 (2017).

174 Pece, A. \& Milani, P. Intravitreal aflibercept for myopic choroidal neovascularization. Graefe's Archive for Clinical and Experimental Ophthalmology 254, 2327-2332 (2016).

175 Wong, T. Y. et al. EFFICACY AND SAFETY OF INTRAVITREAL AFLIBERCEPT AND RANIBIZUMAB IN ASIAN PATIENTS WITH NEOVASCULAR AGE-RELATED MACULAR DEGENERATION: Subgroup Analyses From the View Trials. Retina (Philadelphia, Pa.) (2017). 
176 Cursiefen, C. et al. Aganirsen antisense oligonucleotide eye drops inhibit keratitis-induced corneal neovascularization and reduce need for transplantation: the I-CAN study. Ophthalmology 121, 1683-1692 (2014).

177 Cursiefen, C. et al. GS-101 antisense oligonucleotide eye drops inhibit corneal neovascularization: interim results of a randomized phase II trial. Ophthalmology 116, 16301637 (2009).

178 Rocher, N. et al. Effects of rat anti-VEGF antibody in a rat model of corneal graft rejection by topical and subconjunctival routes. Molecular vision 17, 104 (2011).

179 Bahar, I., Kaiserman, I., McAllum, P., Rootman, D. \& Slomovic, A. Subconjunctival bevacizumab injection for corneal neovascularization. Cornea 27, 142-147 (2008).

180 Jensen, L. et al. in Biomedical Science, Engineering and Technology (InTech, 2012).

181 Cao, R., Jensen, L. D. E., Söll, I., Hauptmann, G. \& Cao, Y. Hypoxia-induced retinal angiogenesis in zebrafish as a model to study retinopathy. PLoS One 3, e2748 (2008).

182 Seng, W. L., Lin, Y., Tang, S. \& Zhong, L. Development of a Hypoxia-Induced Zebrafish Choroidal Neovascularization Model. Zebrafish: Methods for Assessing Drug Safety and Toxicity, 205-218.

183 Huang, C.-C., Lawson, N. D., Weinstein, B. M. \& Johnson, S. L. reg6 is required for branching morphogenesis during blood vessel regeneration in zebrafish caudal fins. Developmental biology 264, 263-274 (2003).

184 Cao, Y. Therapeutic angiogenesis for ischemic disorders: what is missing for clinical benefits? Discovery medicine 9, 179-184 (2010).

185 Paskins-Hurlburt, A. J. \& Hollenberg, N. K. " Tissue need" and limb collateral arterial growth. Skeletal contractile power and perfusion during collateral development in the rat. Circulation research 70, 546-553 (1992).

186 Scott, A. \& Fruttiger, M. Oxygen-induced retinopathy: a model for vascular pathology in the retina. Eye 24, 416 (2010).

187 Birsner, A. E., Benny, O. \& D'Amato, R. J. The corneal micropocket assay: a model of angiogenesis in the mouse eye. Journal of visualized experiments: JoVE (2014).

188 Chen, W.-L. et al. Subconjunctival injection of bevacizumab (avastin) on corneal neovascularization in different rabbit models of corneal angiogenesis. Investigative ophthalmology \& visual science 50, 1659-1665 (2009).

189 Rogers, M. S., Birsner, A. E. \& D'amato, R. J. The mouse cornea micropocket angiogenesis assay. Nature protocols 2, 2545 (2007).

190 Cao, R. et al. Mouse corneal lymphangiogenesis model. Nature protocols 6, 817 (2011).

191 Kenyon, B. M. et al. A model of angiogenesis in the mouse cornea. Investigative ophthalmology \& visual science 37, 1625-1632 (1996).

192 Kalgutkar, A. S., Marnett, A. B., Crews, B. C., Remmel, R. P. \& Marnett, L. J. Ester and amide derivatives of the nonsteroidal antiinflammatory drug, indomethacin, as selective cyclooxygenase-2 inhibitors. Journal of medicinal chemistry 43, 2860-2870 (2000).

193 Gillis, P. et al. Keratinocyte growth factor induces angiogenesis and protects endothelial barrier function. Journal of cell science 112, 2049-2057 (1999).

194 Bai, J.-Q., Qin, H.-F. \& Zhao, S.-H. Research on mouse model of grade II corneal alkali burn. International journal of ophthalmology 9, 487 (2016).

195 Wenk, H. \& Honda, C. Silver nitrate cauterization: characterization of a new model of corneal inflammation and hyperalgesia in rat. Pain 105, 393-401 (2003).

196 Anderson, C., Zhou, Q. \& Wang, S. An alkali-burn injury model of corneal neovascularization in the mouse. Journal of visualized experiments: JoVE (2014).

197 Go, R. S. \& Owen, W. G. in Novel Anticancer Drug Protocols 59-64 (Springer, 2003).

198 Masson, V. et al. Mouse aortic ring assay: a new approach of the molecular genetics of angiogenesis. Biological procedures online 4, 24 (2002).

199 Mohan, R. R., Sharma, A., Netto, M. V., Sinha, S. \& Wilson, S. E. Gene therapy in the cornea. Progress in retinal and eye research 24, 537-559 (2005). 
200 Beverly, M., Hartsough, K., Machemer, L., Pavco, P. \& Lockridge, J. Liquid chromatography electrospray ionization mass spectrometry analysis of the ocular metabolites from a short interfering RNA duplex. Journal of Chromatography B 835, 62-70 (2006).

201 Alexander, S. P. et al. The Concise Guide to Pharmacology 2013/14.: The Concise Guide to Pharmacology 2013/14: Overview. British Journal of Pharmacology 170, 1449 (2013).

202 Birmingham, A. et al. 3' UTR seed matches, but not overall identity, are associated with RNAi off-targets. Nature methods 3, 199 (2006).

203 Jeon, C.-J., Strettoi, E. \& Masland, R. H. The major cell populations of the mouse retina. Journal of Neuroscience 18, 8936-8946 (1998).

204 Panda-Jonas, S., Jonas, J. B., Jakobczyk, M. \& Schneider, U. Retinal photoreceptor count, retinal surface area, and optic disc size in normal human eyes. Ophthalmology 101, 519-523 (1994).

205 Lagali, N. et al. in Confocal Laser Microscopy-Principles and Applications in Medicine, Biology, and the Food Sciences (InTech, 2013).

206 Brown, W. R. A review of string vessels or collapsed, empty basement membrane tubes. Journal of Alzheimer's Disease 21, 725-739 (2010).

207 McDonald, D. M. \& Choyke, P. L. Imaging of angiogenesis: from microscope to clinic. Nature medicine 9, 713 (2003).

208 Cammermeyer, J. Cerebral intervascular strands of connective tissue as routes of transportation. The Anatomical Record 151, 251-259 (1965).

209 Mancuso, M. R. et al. Rapid vascular regrowth in tumors after reversal of VEGF inhibition. The Journal of clinical investigation 116, 2610-2621 (2006).

210 Del Zoppo, G. J. In stroke, complement will get you nowhere. Nature medicine 5, 995 (1999).

211 Fel, A., Aslangul, E. \& Le Jeunne, C. Eye and corticosteroid's use. Presse medicale (Paris, France: 1983) 41, 414-421 (2012).

212 Hoffart, L. et al. Inhibition of corneal neovascularization after alkali burn: comparison of different doses of bevacizumab in monotherapy or associated with dexamethasone. Clinical \& experimental ophthalmology 38, 346-352 (2010).

213 Zaki, A. A. \& Farid, S. F. Subconjunctival bevacizumab for corneal neovascularization. Acta ophthalmologica 88, 868-871 (2010).

214 Dastjerdi, M. H. et al. Topical bevacizumab in the treatment of corneal neovascularization: results of a prospective, open-label, noncomparative study. Archives of Ophthalmology 127, 381-389 (2009).

215 Mohan, R. R., Tovey, J. C., Sharma, A. \& Tandon, A. Gene therapy in the cornea: 2005-present. Progress in retinal and eye research 31, 43-64 (2012).

216 Nguyen, P. \& Yiu, S. C. Strategies for local gene therapy of corneal allograft rejection. Middle East African journal of ophthalmology 20, 11 (2013).

217 Usui, T. et al. Inhibition of corneal neovascularization by blocking the angiotensin II type 1 receptor. Investigative ophthalmology \& visual science 49, 4370-4376 (2008).

218 Fujita, N. et al. Impaired angiogenic response in the corneas of mice lacking osteopontin. Investigative ophthalmology \& visual science 51, 790-794 (2010).

219 Legg, J. A., Herbert, J. M., Clissold, P. \& Bicknell, R. Slits and Roundabouts in cancer, tumour angiogenesis and endothelial cell migration. Angiogenesis 11, 13-21 (2008).

220 Youngblood, V. et al. Elevated Slit2 activity impairs VEGF-induced angiogenesis and tumor neovascularization in EphA2-deficient endothelium. Molecular Cancer Research, molcanres. 0142.2014 (2014).

221 Han, X. \& Zhang, M.-C. Potential anti-angiogenic role of Slit2 in corneal neovascularization. Experimental eye research 90, 742-749 (2010).

222 Kanellis, J. et al. Modulation of inflammation by slit protein in vivo in experimental crescentic glomerulonephritis. The American journal of pathology 165, 341-352 (2004).

223 Lee, W. J. et al. M2 macrophage polarization mediates anti-inflammatory effects of endothelial nitric oxide signaling. Diabetes 64, 2836-2846 (2015). 
224 Hofkens, W., Storm, G., van den Berg, W. \& van Lent, P. Inhibition of M1 macrophage activation in favour of $\mathrm{M} 2$ differentiation by liposomal targeting of glucocorticoids to the synovial lining during experimental arthritis. Annals of the rheumatic diseases 70, A40-A40 (2011).

225 Shirey, K. A. et al. Control of RSV-induced lung injury by alternatively activated macrophages is IL-4R $\alpha-$, TLR4-, and IFN- $\beta$-dependent. Mucosal immunology 3, 291 (2010).

226 Martinez, F. O. \& Gordon, S. The M1 and M2 paradigm of macrophage activation: time for reassessment. F1000prime reports 6 (2014).

227 Stout, R. D. et al. Macrophages sequentially change their functional phenotype in response to changes in microenvironmental influences. The Journal of Immunology 175, 342-349 (2005).

228 Wolfs, I. M., Donners, M. M. \& de Winther, M. P. Differentiation factors and cytokines in the atherosclerotic plaque micro-environment as a trigger for macrophage polarisation. Thrombosis and haemostasis 105, 763-771 (2011).

229 Owen, J. L. \& Mohamadzadeh, M. Macrophages and chemokines as mediators of angiogenesis. Frontiers in physiology 4, 159 (2013).

230 Apte, R. S. in Retinal Degenerative Diseases $15-19$ (Springer, 2010).

231 Jia, W., Kidoya, H., Yamakawa, D., Naito, H. \& Takakura, N. Galectin-3 accelerates M2 macrophage infiltration and angiogenesis in tumors. The American journal of pathology 182, 1821-1831 (2013).

232 Sene, A. et al. Impaired cholesterol efflux in senescent macrophages promotes age-related macular degeneration. Cell metabolism 17, 549-561 (2013).

233 Cursiefen, C., Maruyama, K., Jackson, D. G., Streilein, J. W. \& Kruse, F. E. Time course of angiogenesis and lymphangiogenesis after brief corneal inflammation. Cornea 25, 443-447 (2006).

234 Simons, M., Gordon, E. \& Claesson-Welsh, L. Mechanisms and regulation of endothelial VEGF receptor signalling. Nature Reviews Molecular Cell Biology 17, 611-625 (2016).

235 Noelia, A. \& Castrillo, A. Liver X receptors as regulators of macrophage inflammatory and metabolic pathways. Biochimica et Biophysica Acta (BBA)-Molecular Basis of Disease 1812, 982-994 (2011).

236 Birrell, M. A. et al. Novel role for the liver $\mathrm{X}$ nuclear receptor in the suppression of lung inflammatory responses. Journal of Biological Chemistry 282, 31882-31890 (2007).

$237 \mathrm{Yu}, \mathrm{S}$. et al. Dissociated sterol-based liver $\mathrm{X}$ receptor agonists as therapeutics for chronic inflammatory diseases. The FASEB Journal 30, 2570-2579 (2016).

238 Yang, H. et al. Activation of liver $\mathrm{X}$ receptor alleviates ocular inflammation in experimental autoimmune uveitis. Investigative ophthalmology \& visual science 55, 2795-2804 (2014).

239 Walcher, D. et al. LXR activation reduces proinflammatory cytokine expression in human CD4positive lymphocytes. Arteriosclerosis, thrombosis, and vascular biology 26, 1022-1028 (2006).

240 Cui, W. et al. Liver $X$ receptor activation attenuates inflammatory response and protects cholinergic neurons in APP/PS1 transgenic mice. Neuroscience 210, 200-210 (2012).

241 Joseph, S. B., Castrillo, A., Laffitte, B. A., Mangelsdorf, D. J. \& Tontonoz, P. Reciprocal regulation of inflammation and lipid metabolism by liver $X$ receptors. Nature medicine 9, 213 (2003).

$242 \mathrm{Im}, \mathrm{S} .-\mathrm{S}$. \& Osborne, T. F. Liver $\mathrm{x}$ receptors in atherosclerosis and inflammation. Circulation research 108, 996-1001 (2011).

243 Watari, K. et al. Role of macrophages in inflammatory lymphangiogenesis: enhanced production of vascular endothelial growth factor C and D through NF-KB activation. Biochemical and biophysical research communications 377, 826-831 (2008).

244 Ghisletti, S. et al. Cooperative NCoR/SMRT interactions establish a corepressor-based strategy for integration of inflammatory and anti-inflammatory signaling pathways. Genes \& development 23, 681-693 (2009).

245 Ito, A. et al. LXRs link metabolism to inflammation through Abca1-dependent regulation of membrane composition and TLR signaling. Elife 4 (2015). 
246 Beyea, M. M. et al. Selective up-regulation of LXR-regulated genes ABCA1, ABCG1, and APOE in macrophages through increased endogenous synthesis of 24 (S), 25-epoxycholesterol. Journal of Biological Chemistry 282, 5207-5216 (2007).

247 Pourcet, B. et al. The nuclear receptor LXR modulates interleukin-18 levels in macrophages through multiple mechanisms. Scientific reports 6, 25481 (2016).

248 Hammer, S. S. et al. The Mechanism of Diabetic Retinopathy Pathogenesis Unifying Key Lipid Regulators, Sirtuin 1 and Liver X Receptor. EBioMedicine 22, 181-190 (2017).

249 Schultz, J. R. et al. Role of LXRs in control of lipogenesis. Genes \& development 14, 2831-2838 (2000).

250 Lim, R. K. et al. Targeted Delivery of LXR Agonist Using a Site-Specific Antibody-Drug Conjugate. Bioconjugate chemistry 26, 2216-2222 (2015).

251 Schrage, N. F., Frentz, M. \& Reim, M. Changing the composition of buffered eye-drops prevents undesired side effects. British Journal of Ophthalmology, bjo. 2009.177386 (2010).

252 Peebo, B. B., Fagerholm, P., Traneus-Röckert, C. \& Lagali, N. Cellular level characterization of capillary regression in inflammatory angiogenesis using an in vivo corneal model. Angiogenesis 14, 393 (2011).

253 Kirat, O. M. \& Al-Dhibi, H. A. Regression of aggressive corneal vascularization after photodynamic therapy, subconjunctival Avastin injections and topical cyclosporin-A $1 \%$ drops: A case report. Saudi Journal of Ophthalmology 24, 151-154 (2010).

254 Cajal, S. R. Contribution a la connaissance de la névroglie cérébrale et cérébelleuse dans la paralysie générale progressive. Avec quelques indications techniques sur I 'imprégnation argentique du tissu nerveux pathologique. Trab Lab Invest Biol Univ Madrid 23, 157-216 (1925).

255 Klintworth, G. K. Corneal angiogenesis: a comprehensive critical review. (Springer Science \& Business Media, 2012).

256 Arbiser, J. L. Angiogenesis-Based Dermatology. (Springer, 2017).

257 Faraj, L. A., Said, D. G., Al-Aqaba, M., Otri, A. M. \& Dua, H. S. Clinical evaluation and characterisation of corneal vascularisation. British Journal of Ophthalmology, bjophthalmol2015-306686 (2015).

258 Sandison, J. Observations on the growth of blood vessels as seen in the transparent chamber introduced into the rabbit's ear. Developmental Dynamics 41, 475-496 (1928).

259 Archer, D. B. Responses of retinal and choroidal vessels to ionising radiation. Eye 7, 1 (1993).

260 REINECKE, R. D., KUWABARA, T., COGAN, D. G. \& WEIS, D. R. Retinal vascular patterns: part V: experimental ischemia of the cat eye. Archives of ophthalmology 67, 470-475 (1962).

261 de Venecia, G., Davis, M. \& Engerman, R. Clinicopathologic correlations in diabetic retinopathy: I. Histology and fluorescein angiography of microaneurysms. Archives of Ophthalmology 94, 1766-1773 (1976).

262 Kohner, E. M. \& Henkind, P. Correlation of fluorescein angiogram and retinal digest in diabetic retinopathy. American journal of ophthalmology 69, 403-414 (1970).

$263 \mathrm{Gu}$, Y., Dee, C. M. \& Shen, J. Interaction of free radicals, matrix metalloproteinases and caveolin-1 impacts blood-brain barrier permeability. Front Biosci (Schol Ed) 3, 1216-1231 (2011).

264 Montezano, A. C. \& Touyz, R. M. Reactive oxygen species, vascular Noxs, and hypertension: focus on translational and clinical research. Antioxidants \& redox signaling 20, 164-182 (2014).

265 Intengan, H. D. \& Schiffrin, E. L. Vascular remodeling in hypertension: roles of apoptosis, inflammation, and fibrosis. Hypertension 38, 581-587 (2001).

266 Inai, T. et al. Inhibition of vascular endothelial growth factor (VEGF) signaling in cancer causes loss of endothelial fenestrations, regression of tumor vessels, and appearance of basement membrane ghosts. The American journal of pathology 165, 35-52 (2004).

267 Caja, S. \& Enríquez, J. A. Mitochondria in endothelial cells: sensors and integrators of environmental cues. Redox biology 12, 821-827 (2017). 
268 Shalinsky, D. et al. Broad antitumor and antiangiogenic activities of AG3340, a potent and selective MMP inhibitor undergoing advanced oncology clinical trials. Annals of the New York Academy of Sciences 878, 236-270 (1999).

269 Clark, A. F. \& Wordinger, R. J. The role of steroids in outflow resistance. Experimental eye research 88, 752-759 (2009).

270 Petersen, A., Carlsson, T., Karlsson, J., Jonhede, S. \& Zetterberg, M. Effects of dexamethasone on human lens epithelial cells in culture. Molecular vision 14, 1344 (2008).

271 Langer, H. F. et al. Complement-mediated inhibition of neovascularization reveals a point of convergence between innate immunity and angiogenesis. Blood 116, 4395-4403 (2010).

272 Khan, M. A., Assiri, A. \& Broering, D. Complement and macrophage crosstalk during process of angiogenesis in tumor progression. Journal of biomedical science 22, 58 (2015).

273 Atkinson, J. P. \& Farries, T. Separation of self from non-self in the complement system. Immunology today 8, 212-215 (1987).

274 Liszewski, M. K., Farries, T. C., Lublin, D. M., Rooney, I. A. \& Atkinson, J. P. Control of the complement system. Advances in immunology 61, 201-283 (1996).

275 Bora, N. S., Matta, B., Lyzogubov, V. V. \& Bora, P. S. Relationship between the complement system, risk factors and prediction models in age-related macular degeneration. Molecular immunology 63, 176-183 (2015).

276 Anderson, D. H., Mullins, R. F., Hageman, G. S. \& Johnson, L. V. A role for local inflammation in the formation of drusen in the aging eye. American journal of ophthalmology 134, 411-431 (2002).

277 Reynolds, R. et al. Plasma complement components and activation fragments: associations with age-related macular degeneration genotypes and phenotypes. Investigative ophthalmology \& visual science 50, 5818-5827 (2009). 
5. APPENDIX: Publications and a manuscript used in the thesis 



\section{Papers}

The papers associated with this thesis have been removed for copyright reasons. For more details about these see:

http://urn.kb.se/resolve?urn=urn:nbn:se:liu:diva-147979 